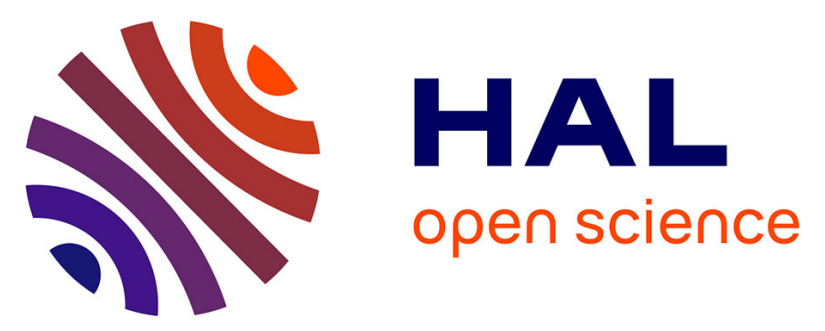

\title{
Syndioselective ring-opening polymerization and copolymerization of trans-1,4-cyclohexadiene carbonate mediated by achiral metal- and organo-catalysts
}

Abdou Khadri Diallo, Evgueni Kirillov, Martine Slawinski, Jean-Michel

Brusson, Sophie M Guillaume, Jean-François Carpentier

\section{To cite this version:}

Abdou Khadri Diallo, Evgueni Kirillov, Martine Slawinski, Jean-Michel Brusson, Sophie M Guillaume, et al.. Syndioselective ring-opening polymerization and copolymerization of trans-1,4-cyclohexadiene carbonate mediated by achiral metal- and organo-catalysts. Polymer Chemistry, 2015, 6 (11), pp.19611971. 10.1039/C4PY01713G . hal-01115003

HAL Id: hal-01115003

https://hal-univ-rennes1.archives-ouvertes.fr/hal-01115003

Submitted on 26 May 2015

HAL is a multi-disciplinary open access archive for the deposit and dissemination of scientific research documents, whether they are published or not. The documents may come from teaching and research institutions in France or abroad, or from public or private research centers.
L'archive ouverte pluridisciplinaire HAL, est destinée au dépôt et à la diffusion de documents scientifiques de niveau recherche, publiés ou non, émanant des établissements d'enseignement et de recherche français ou étrangers, des laboratoires publics ou privés. 


\section{Syndioselective Ring-Opening Polymerization and Copolymerization of}

\section{Trans-1,4-Cyclohexadiene Carbonate Mediated by Achiral Metal- and}

\section{Organo-Catalysts}

Abdou Khadri Diallo, ${ }^{a}$ Evgueni Kirillov, ${ }^{a}$ Martine Slawinski, ${ }^{b}$ Jean-Michel Brusson, ${ }^{c}$ Sophie

M. Guillaume ${ }^{a}$ and Jean-François Carpentier ${ }^{a, *}$

${ }^{a}$ Institut des Sciences Chimiques de Rennes, UMR 6226 CNRS-Université de Rennes 1, Campus de Beaulieu, F-35042 Rennes Cedex, France

${ }^{b}$ Total Raffinage Chimie Feluy, Zone Industrielle Feluy C, B-7181 Seneffe, Belgium

${ }^{c}$ Total S.A., Corporate Science, Tour Michelet A, 24 Cours Michelet - La Défense 10, 92069

Paris La Défense Cedex, France

* Corresponding author: jean-francois.carpentier@univ-rennes1.fr 
Abstract: The ring-opening polymerization (ROP) of trans-1,4-cyclohexadiene carbonate (CHDC) has been investigated computationally and experimentally. DFT computations indicate that ring-opening of CHDC is thermodynamically possible, yet to a lesser extent than that of trans-cyclohexene carbonate (CHC). Effective homopolymerizations of rac-CHDC and simultaneous or sequential copolymerizations of rac-CHDC with rac-CHC and L-LA were achieved with a diaminophenolate zinc-based complex ([(NNO)ZnEt]) or a guanidine (TBD) associated with an alcohol. These ROP reactions, which confirmed the lower reactivity of rac-CHDC vs. rac-CHC, especially in homopolymerization, proceeded without any decarboxylation. Quite uniquely, highly syndiotactic PCHDC was obtained from ROP of racCHDC with both the zinc- and TBD-based catalysts, as revealed by ${ }^{13} \mathrm{C}\left\{{ }^{1} \mathrm{H}\right\}$ NMR studies. The prepared homopolymers and block or random copolymers were characterized by ${ }^{1} \mathrm{H}$, ${ }^{13} \mathrm{C}\left\{{ }^{1} \mathrm{H}\right\}$ NMR, MALDI-ToF-MS, SEC and DSC techniques.

Keywords: Cyclic Carbonate, Ring-Opening Polymerization, Stereoselectivity, DFT 


\section{Introduction}

Aromatic and aliphatic polycarbonates (PCs) are important commodity and engineering materials used in a variety of applications. Classic aromatic PCs derived from bisphenol A (BPA) show valuable thermo-mechanical properties; however, they have raised major concerns related to the toxicity of the latter BPA monomer and of phosgene used as the coreagent. Although aliphatic PCs do not have properties that match yet those of aromatic PCs derived from BPA, this class of polymers has attracted much interest in recent years. Indeed, depending on the chemical repeat units and the microstructure, some of these polymers show promising thermal properties (e.g., high $T_{\mathrm{g}}$ and $\left.T_{\mathrm{m}}\right) .{ }^{1}$ Also, thanks to their functional termini, they can serve as valuable pre-polymers for the production of other important materials (e.g., polyurethanes from dihydroxy-telechelic low molar mass pre-polymers ${ }^{2}$ ). Moreover, besides the traditional, yet poorly controlled polycondensation reaction between a dialkyl carbonate and an $\alpha, \omega$-diol, ${ }^{3}$ aliphatic PCs can be more effectively produced by two alternative routes: a) the metal-catalyzed alternating ring-opening copolymerization (ROCOP) of epoxides $/ \mathrm{CO}_{2}$, and b) the ring-opening polymerization (ROP) of cyclic carbonate monomers (Scheme 1).

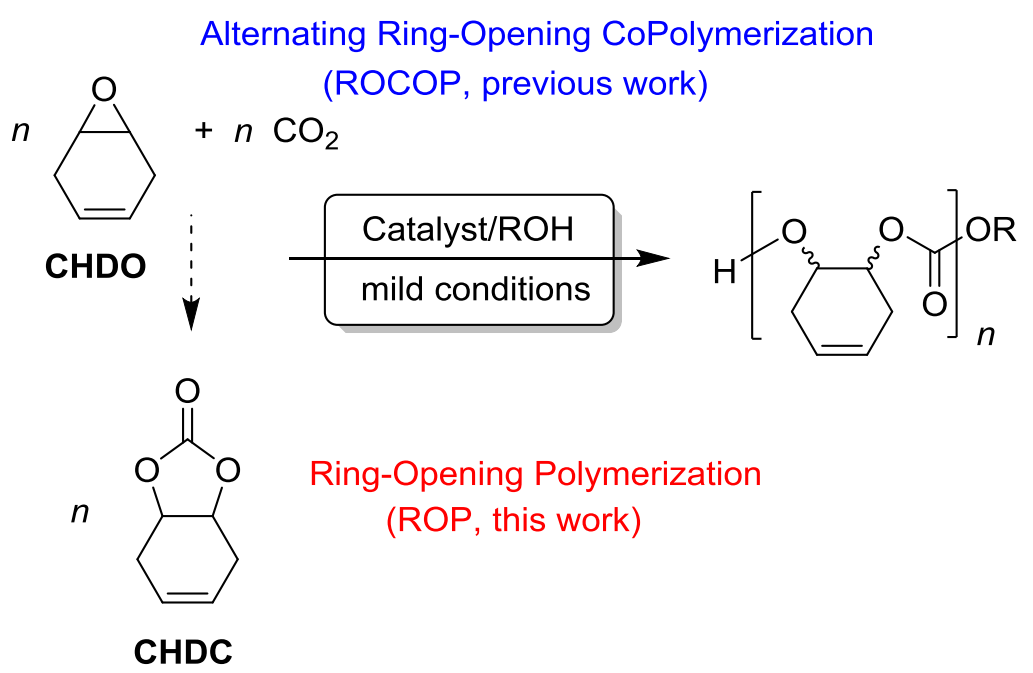


Scheme 1. ROCOP and ROP routes toward polycarbonates, illustrated with cyclohexadiene oxide (CHDO) and cyclohexadiene carbonate (CHDC) for the formation of poly(cyclohexadiene carbonate) (PCHDC).

ROCOP's attractive features include the use of carbon dioxide, the possibility to reach high molar mass polymers, and also to access sometimes high stereoselectivities via desymmetrization of achiral meso epoxides with chiral catalysts. ${ }^{4}$ On the other hand, ROCOP faces the issue of incomplete alternating selectivities, which may result in the formation of ether units along the PC chain, and also the formation, alongside the PC, of the corresponding five-membered ring cyclic carbonate $(5 \mathrm{CC})$ monomer. A large number of ROCOP studies involved cyclohexene oxide $(\mathrm{CHO})$ and hence led to the production of poly(cyclohexene carbonate) (PCHC), along with variable amounts of its corresponding 5CC monomer (i.e., cyclohexene carbonate, $\mathrm{CHC}){ }^{5}$ Whereas the vast majority of catalysts for $\mathrm{CHO} / \mathrm{CO}_{2} \mathrm{ROCOP}$ promote the formation of atactic $\mathrm{PCHC}$, some of them, essentially $\mathrm{Zn}, \mathrm{Cr}$ or Co complexes based on chiral salen or $\beta$-diketiminate derivatives, enable the synthesis of syndiotactic- (up to $81 \%$ of $r$-centered tetrads $)^{6}$ or isotactic- (up to $\left.(R, R) /(S, S)=98: 2\right)^{7}$ enriched PCHCs.

ROP of cyclic carbonates (CCs) is another privileged procedure to access welldefined, high molar mass aliphatic PCs. ${ }^{8}$ Given the ready availability of a large number of 5CCs from epoxide carboxylation (vide supra) or from biosourced 1,2-diols, ${ }^{9}$ the valorization of these monomers into PCs certainly deserves consideration. Yet, whereas six- and, to a lesser extent, seven-membered ring $\mathrm{CCs}$ have been quite selectively polymerized by ROP under mild operating conditions, the related 5CCs have hardly been ring-opened (co)polymerized. ${ }^{10}$ This is obviously related to their small ring-strain and poor polymerizability, ${ }^{11}$ which is intimately associated to their abovementioned easy formation. Hence, although several ROP catalyst systems have been identified for the copolymerization 
of ubiquitous 5CCs such as ethylene and propylene carbonates, the reactions proceed only at high temperatures with poor-to-modest 5CC conversion, and they are always accompanied by a partial or total decarboxylation of the latter monomer. ${ }^{10}$ On the other hand, there are a few examples of strained 5CCs which can undergo selective ROP. Endo and coworkers first performed the successful ROP of the sugar-derived 5CC, methyl 4,6-O-benzylidene-2,3-Ocarbonyl- $R$-D-glucopyranoside, without decarboxylation using $n$-BuLi, $\mathrm{MO} t \mathrm{Bu}(\mathrm{M}=\mathrm{Li}, \mathrm{Na}$, K) or DBU as initiators $\left(M_{\mathrm{n}, \mathrm{SEC}}\right.$ up to $\left.20200 \mathrm{~g} \cdot \mathrm{mol}^{-1}, \bigoplus_{\mathrm{M}}=c a .1 .8\right) .{ }^{12} \mathrm{Also}$, we have reported recently the easy and efficient ROP of trans-cyclohexene carbonate (CHC). ${ }^{13}$ PCHCs with controlled molar masses $\left(M_{\mathrm{n}, \mathrm{NMR}}\right.$ up to $17000 \mathrm{~g} \cdot \mathrm{mol}^{-1}, \bigoplus_{\mathrm{M}}=c a$. 1.2) and a slight isotactic bias $\left(P_{\mathrm{m}}\right.$ up to $\left.76 \%\right)$ were obtained by ROP of the racemic monomer ( $\left.r a c-\mathrm{CHC}\right)$ catalyzed by zinc diaminophenolate, zinc $\beta$-diketiminate, yttrium bis(phenolate) complexes, or 1,5,7triazabicyclo[4.4.0]dec-5-ene (TBD), in combination with an alcohol as a co-initiator. Purely isotactic PCHC was synthesized for the first time via ROP of enantiopure $(R, R)$-CHC with a zinc/benzyl alcohol catalyst system. Parallel to the work of Haba et al. who used $t$ BuOLi to initiate the ROP of $\mathrm{CHC},{ }^{14}$ we unveiled the determining impact of the fused trans-cyclohexyl ring-strain to enable the $\mathrm{ROP}$ of $\mathrm{CHC}$, as opposed to meso-CHC which is unreactive.

In this contribution, we now report that the ROP of trans-cyclohexadiene carbonate (trans-1,2-cyclohex-4-enyl cyclocarbonate, trans-CHDC, Scheme 1) can be performed also by various metal-based or organo-catalysts. The corresponding poly(cyclohexadiene carbonate) (PCHDC) has just been recently reported by the ROCOP route from meso-CHDO (cyclohexadiene oxide, that is 1,2-epoxy-4-cyclohexene, Scheme 1) ${ }^{15}$ and was obtained in a non-stereoselective manner. Quite uniquely, we evidence that the ROP of rac-CHDC, despite the use of non-chiral catalysts, affords pure syndiotactic PCHDCs; besides; highly isotactic PCHDC has been prepared independently from enantio-enriched trans-CHDC. The effective preparation of copolymers of CHDC with $\mathrm{CHC}$ and $L$-lactide is presented as well. 


\section{Experimental section}

Computational Details. All DFT calculations were carried out using the Gaussian09 program suite, ${ }^{16}$ employing the M06 functional, ${ }^{17}$ and using a standard double- $\xi$ polarized basis set, namely the $6-31(\delta, \pi)$ set. ${ }^{18}$ All stationary points were fully characterized via analytical frequency calculations as true minima (all positive eigen values). Enthalpies were obtained at $\mathrm{T}=298 \mathrm{~K}$ within the harmonic approximation.

\section{Methods and Instrumentation}

NMR spectra were recorded on a AM-400 Bruker spectrometers at $298 \mathrm{~K}$ in $\mathrm{CDCl}_{3}$. A relaxation delay of $3 \mathrm{~s}$ was used during the acquisition to yield quantitative ${ }^{1} \mathrm{H}$ NMR spectra. The chemical shifts were referenced to tetramethylsilane (TMS) using the residual protiosolvent $\left({ }^{1} \mathrm{H}\right)$ or the carbon $\left({ }^{13} \mathrm{C}\right)$ resonance of the deuterated solvent.

Monomer conversions were determined from ${ }^{1} \mathrm{H}$ NMR spectra of the crude polymer samples, from the integration (Int.) ratio Int.Polym/[Int.Polym+Int.Monom], typically using the methine and methylene hydrogens.

Molar masses $\left(M_{\mathrm{n}}\right.$ and $\left.M_{\mathrm{w}}\right)$ and dispersities $\left(\bigoplus_{\mathrm{M}}=M_{\mathrm{w}} / M_{\mathrm{n}}\right)$ of polymers and copolymers were determined by size exclusion chromatography (SEC) using a Polymer Laboratories PL-GPC 50 instrument equipped with a set of two ResiPore Mixed E $300 \times 7.5$ mm columns and a refractive index detector. The sample was eluted with $\mathrm{CHCl}_{3}$ (PCHDC) or THF (copolymers) at $30{ }^{\circ} \mathrm{C}$ at $1.0 \mathrm{~mL} \cdot \mathrm{min}^{-1}$ and the calibration was carried out using 11 monodisperse polystyrene standards $\left(M_{\mathrm{n}}\right.$ range from 580 to $\left.380,000 \mathrm{~g} \cdot \mathrm{mol}^{-1}\right)$. 
Differential scanning calorimetry (DSC) analyses were performed on a Setaram DSC 131 apparatus calibrated with indium at a rate of $10^{\circ} \mathrm{C} \cdot \mathrm{min}^{-1}$, under continuous flow of helium (25 mL.min $\left.{ }^{-1}\right)$, using aluminum capsules (typically $10 \mathrm{mg}$ of polymer).

\section{Syntheses}

All manipulations were performed under inert atmosphere (argon, $<3 \mathrm{ppm} \mathrm{O}_{2}$ ) using standard Schlenk, vacuum line, and glovebox techniques. Benzyl alcohol and isopropanol were distilled over Mg turnings under argon atmosphere and kept over activated 3-4 A molecular sieves. Complex [(NNO)ZnEt] was synthesized following the literature procedure. ${ }^{21} 1,5,7-$ Triazabicyclo[4.4.0]dec-5-ene (TBD) (98\%, Aldrich) and $\mathrm{Y}\left[\mathrm{N}\left(\mathrm{SiMe}_{3}\right)_{2}\right]_{3}(98 \%$, Strem Chem.) were used as received. Racemic trans-cyclohexene carbonate ( $\mathrm{rac}-\mathrm{CHC}$ ) was prepared as previously reported. Technical grade $L$-lactide ( $L$-LA) was provided by Total Raffinage Chimie and purified by recrystallization from a hot $\left(80^{\circ} \mathrm{C}\right)$, concentrated isopropanol solution, followed by two subsequent recrystallizations in hot $\left(105{ }^{\circ} \mathrm{C}\right)$ toluene. After purification, $L$-LA was stored at all times at a temperature of $-30{ }^{\circ} \mathrm{C}$ in the inert atmosphere of the glove-box. Trans-racemic-1,2-cyclohex-4-enediol was prepared from cyclohexadiene following the reported literature procedure. ${ }^{19}$

Trans-(R,R)-1,2-cyclohex-4-ene-diol (enantio-enriched, 83\% ee) was obtained by resolution of the racemic product (Scheme 3) following the same procedure used for 1,2cyclohexanediol. ${ }^{20}$ A round-bottom flask was charged with dicyclohexylcarbodiimide (DCC; $2.00 \mathrm{~g}, 9.64 \mathrm{mmol}),( \pm)$-trans-cyclohex-4-ene-1,2-diol $(1.00 \mathrm{~g}, 8.76 \mathrm{mmol})$ and $\mathrm{N}, \mathrm{N}$ dimethylaminopyridine (DMAP) (0.107 g, $8.76 \mathrm{mmol})$. Freshly distilled THF (20 mL) was introduced into the flask under an argon atmosphere, and the solution was cooled at $-10{ }^{\circ} \mathrm{C}$. A solution of $(S)-(+)-O$-acetylmandelic acid $(1.70 \mathrm{~g}, 8.76 \mathrm{mmol})$ in THF $(10 \mathrm{~mL})$ was slowly added in. Stirring was maintained over $6 \mathrm{~h}$ until the completion of the reaction (TLC 
monitoring). The reaction mixture was filtered to remove the urea derivative; the filtrate was evaporated under vacuum to obtain a colorless liquid, which was chromatographed using silica gel and 20\% EtOAc/petroleum ether as eluent. The first fraction (minor fraction, the other one was discarded) was collected and the solvent was removed under vacuum $(0.30 \mathrm{~g}$, $30 \%)$. This product was stirred in a $1 \mathrm{~N}$ methanolic $\mathrm{NaOH}$ solution $(20 \mathrm{~mL})$ at room temperature for $4 \mathrm{~h}$. After disappearance of the ester (TLC monitoring), $\mathrm{MeOH}$ was evaporated, the crude product was purified through Kugelrohr distillation $\left(200{ }^{\circ} \mathrm{C}, 4 \mathrm{~mm} \mathrm{Hg}\right.$ ) and re-crystallized from benzene. Trans-(R,R)-1,2-cyclohex-4-ene-diol was obtained as a white solid $(0.276 \mathrm{~g}, 92 \%$ for this step). Enantiomeric excess ( $83 \%$ ee) was measured by chiral GC using a Beta-dex column, helium $\left(40.0 \mathrm{~cm} \cdot \mathrm{s}^{-1}\right), 90{ }^{\circ} \mathrm{C}$ to $160{ }^{\circ} \mathrm{C}$ at $2{ }^{\circ} \mathrm{C} \cdot \mathrm{min}^{-1}$, $\mathrm{R}_{\mathrm{t}}(S, S)=19.6 \min , \mathrm{R}_{\mathrm{t}}(R, R)=20.1 \min ($ Figure $\mathrm{S} 1)$.

( \pm )-Trans-1,2-cyclohex-4-enyl cyclocarbonate (rac-CHDC). A solution of triethylamine $(10.8 \mathrm{~mL}, 79 \mathrm{mmol})$ in THF $(30 \mathrm{~mL})$ was added dropwise at $0{ }^{\circ} \mathrm{C}$ to a solution of ( \pm -trans-cyclohex-4-ene-1,2-diol (4.00 g, $35 \mathrm{mmol})$ and ethyl chloroformate $(7.5 \mathrm{~mL}, 79$ mmol) in THF $(60 \mathrm{~mL})$. Once the addition completed, the reaction mixture was stirred at $23 \pm$ $2{ }^{\circ} \mathrm{C}$ over $6 \mathrm{~h}$. The mixture was next filtered to remove the formed ammonium salt, and THF was removed under vacuum. The crude product was purified by flash column chromatography (pentane/ethyl acetate: 100:0 to 80:20), and then recrystallized three times from diethyl ether to give ( \pm -trans-CHDC as thin white crystalline needles $(3.43 \mathrm{~g}, 70 \%) . \mathrm{M}_{\mathrm{p}}=128{ }^{\circ} \mathrm{C} ;{ }^{1} \mathrm{H}$ NMR $\left(\mathrm{CDCl}_{3}, 400 \mathrm{MHz}, 23{ }^{\circ} \mathrm{C}\right.$, Figure S2): $\delta(\mathrm{ppm}) 5.67\left(\mathrm{~d}, 2 \mathrm{H}, \mathrm{CH}_{2} \mathrm{CH}=\mathrm{CHCH}_{2}\right), 4.27(\mathrm{~m}$, $\left.2 \mathrm{H}, \mathrm{CH}_{2} \mathrm{CHOC}(=\mathrm{O}) \mathrm{OCHCH}_{2}\right), 2.64-2.70(\mathrm{~m}, 2 \mathrm{H}, \mathrm{CH} \mathrm{HCH}=\mathrm{CHCHH}), 2.40-2.48(\mathrm{~m}, 2 \mathrm{H}$, $C H \mathrm{HCH}=\mathrm{CHCHH}) ;{ }^{13} \mathrm{C}\left\{{ }^{1} \mathrm{H}\right\} \mathrm{NMR}\left(\mathrm{CDCl}_{3}, 100 \mathrm{MHz}, 23{ }^{\circ} \mathrm{C}\right.$, Figure S3): $\delta(\mathrm{ppm}) 154.9$ $(\mathrm{OC}(=\mathrm{O}) \mathrm{O}), \quad 124.1 \quad\left(\mathrm{CH}_{2} \mathrm{CH}=\mathrm{CHCH}_{2}\right), \quad 79.8 \quad\left(\mathrm{CH}_{2} \mathrm{CH}(\mathrm{CH})(\mathrm{OC}(=\mathrm{O}))\right), \quad 29.6 \quad\left(\mathrm{CH}_{2^{-}}\right.$ $\mathrm{CH}=\mathrm{CHCH}_{2}$ ). 
Trans-(R,R)-1,2-cyclohex-4-enyl cyclocarbonate $((\boldsymbol{R}, \boldsymbol{R})-\mathrm{CHDC})$ was obtained similarly. The product was recrystallized twice before use in ROP. $\mathrm{M}_{\mathrm{p}}=128^{\circ} \mathrm{C},[\alpha]_{\mathrm{D}}{ }^{20}=$ $-81.5\left(c\right.$ 0.36, $\left.\mathrm{CH}_{2} \mathrm{Cl}_{2}\right)$; ${ }^{1} \mathrm{H}$ NMR (Figure S4) and ${ }^{13} \mathrm{C}$ NMR (Figure S5) spectra are identical to those of rac-CHDC.

Typical procedure for the ROP of rac-CHDC promoted by [(NNO)ZnEt] / BnOH. A similar procedure was followed for the synthesis of $\mathrm{PCHDC}$ with $\mathrm{Y}\left[\mathrm{N}(\mathrm{SiMe})_{2}\right]_{3}$ or TBD as catalyst. Typically, [(NNO)ZnEt] (4.0 mg, $9.3 \mu \mathrm{mol}, 1$ equiv.) was added to $\mathrm{BnOH}$ (1 equiv., as a stock solution in toluene) and stirred at room temperature over $15 \mathrm{~min}$, just prior to the addition of rac-CHDC (64 $\mathrm{mg}, 0.46 \mathrm{mmol}, 50$ equiv) and the quantity of toluene necessary to reach a concentration of $4 \mathrm{M}$ (Table 1 , entry 1 ). The mixture was then stirred at $60{ }^{\circ} \mathrm{C}$ over the appropriate time period (reaction times were not optimized). The polymerization was then stopped upon addition of an acetic acid solution $\left(\mathrm{ca} .0 .05 \mathrm{~mL}\right.$ of a $1.6 \mathrm{~mol} . \mathrm{L}^{-1}$ solution in toluene) and the volatiles removed under vacuum. After determination of the CHDC conversion by ${ }^{1} \mathrm{H}$ NMR analysis of this crude product, the resulting mixture was dissolved in $\mathrm{CH}_{2} \mathrm{Cl}_{2}$, and the polymer was purified upon precipitation (when a significant conversion could be achieved) in cold methanol, filtered and dried under vacuum. The isolated PCHC was then analysed by NMR, SEC, and DSC. ${ }^{1} \mathrm{H}$ and ${ }^{13} \mathrm{C}$ NMR spectra of PCHDC homopolymers are available in the Supporting Information (Figures S6-S11).

Simultaneous Copolymerization of rac-CHDC with rac-CHC or L-LA with [(NNO)ZnEt] / BnOH. The polymerizations were conducted as described above using a mixture of the two monomers. The $\mathrm{P}(\mathrm{CHC}-\mathrm{co}$-PCHDC) and $\mathrm{P}(\mathrm{LLA}-\mathrm{co}$-PCHDC) copolymers were isolated by re-precipitation with methanol from a $\mathrm{CH}_{2} \mathrm{Cl}_{2}$ solution and then analysed by ${ }^{1} \mathrm{H}$ NMR, ${ }^{13} \mathrm{C}$ NMR, SEC and DSC (see the Supporting Information).

Sequential Copolymerization of rac-CHC with rac-CHDC with [(NNO)ZnEt] / BnOH. The homopolymerization was conducted as described above for rac-CHDC. Rac- 
$\mathrm{CHC}$ was polymerized first over $6 \mathrm{~h}$. After this time period, a small aliquot was sampled under controlled atmosphere to determine the monomer conversion and the molecular mass of the formed PCHC, and rac-CHDC was then introduced in the reaction mixture. The reaction was continued for $3 \mathrm{~h}$. The same workup as above was then applied. The P(CHC-co-PCHDC) and P(LLA-co-PCHDC) copolymers were isolated by re-precipitation with methanol from a $\mathrm{CH}_{2} \mathrm{Cl}_{2}$ solution and then analysed by ${ }^{1} \mathrm{H}$ NMR, ${ }^{13} \mathrm{C}$ NMR, SEC and DSC (see the Supporting information).

\section{Results and Discussion}

Preliminary DFT computations. In order to get a first hint, we assessed the polymerizability of the trans and meso diastereoisomers of CHDC via DFT computations. As for our prior work on the ROP of $\mathrm{CHC},{ }^{13 \mathrm{a}}$ the ring-opening of these two molecules by methanol was used as a simple model (Scheme 2). Given the generally accepted uncertainty of $\pm 2 \mathrm{kcal}^{\mathrm{m}} \mathrm{mol}^{-1}$ for DFT computations, the calculated $\Delta G^{\circ}$ value of $+0.8 \mathrm{kcal} . \mathrm{mol}^{-1}$ suggests that trans-CHDC may be thermodynamically ring-opened. In contrast, for meso-CHDC which is obviously less strained than the trans diastereomer, the clearly endergonic $\Delta G^{\circ}$ value of $+6.4 \mathrm{kcal} . \mathrm{mol}^{-1}$ indicates its non-polymerizability. These ring-opening energy values are unfavorably shifted from the corresponding ones determined for trans-CHC $\left(\Delta G^{\circ}=-3.6 \mathrm{kcal} . \mathrm{mol}^{-1}\right)$ and $m e s o$ $\mathrm{CHC}\left(\Delta G^{\circ}=+2.6 \mathrm{kcal}^{\mathrm{m}} \mathrm{mol}^{-1}\right)$, suggesting a lower polymerizabilty of CHDC as compared to $\mathrm{CHC} ;{ }^{13 \mathrm{a}}$ of note, the $\Delta G^{\circ}$ trans $/ \Delta G^{\circ}$ meso energy difference is similar for both CHDC and CHC (5.5-6.2 kcal.mol $\left.{ }^{-1}\right)$. As we previously confirmed experimentally that meso-CHC is indeed not polymerizable in contrast to trans-CHC (in line with DFT computations), ${ }^{13 a}$ we thus decided to focus our experimental investigations on trans-CHDC. 

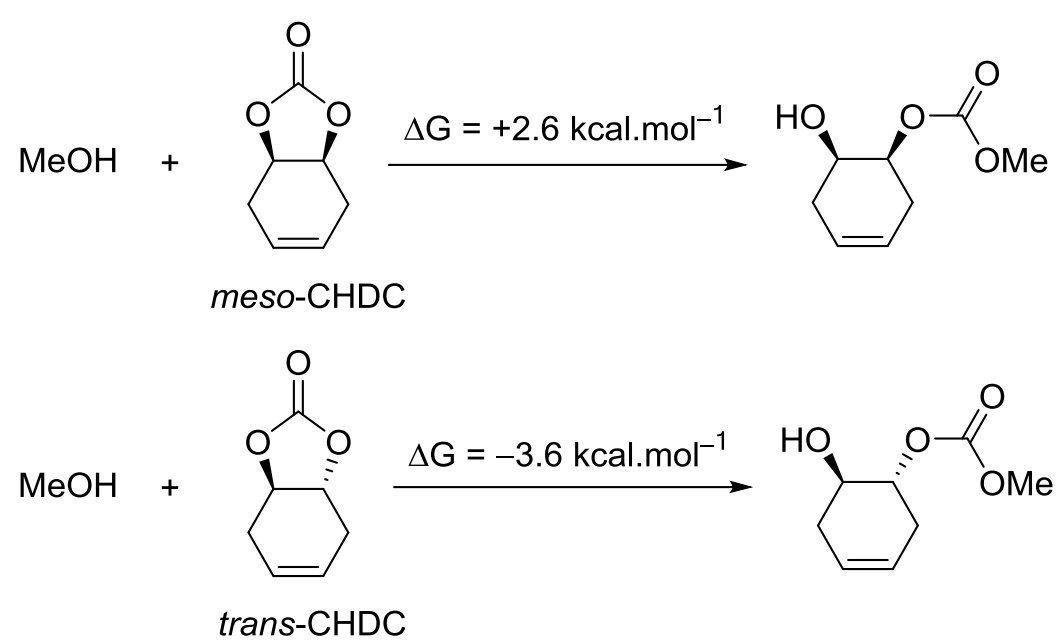

Scheme 2. Model reactions used for DFT computations of ring-opening of meso- and transCHDC.

\section{Experimental investigations on the ROP of trans-CHDC}

Homopolymerization. Homopolymerization of trans-CHDC was first investigated with a series of ROP catalyst systems that previously proved to be quite efficient towards cyclic esters and carbonates, and notably trans-CHC. These include the binary systems based on the zinc diaminophenolate complex $[(\mathrm{NNO}) \mathrm{ZnEt}],{ }^{21}$ the simple homoleptic $\mathrm{Y}\left(\mathrm{N}\left(\mathrm{SiMe}_{3}\right)_{2}\right)_{3},{ }^{22}$ or guanidine TBD, all combined to benzyl alcohol $(\mathrm{BnOH})$ or isopropyl alcohol $(i \mathrm{PrOH})$ as coinitiator (Scheme 3). In order to assess the stereoselectivity of the polymerizations, the ROP of trans-(R,R)-CHDC was investigated in parallel to that of the trans-racemic monomer. Trans- $(R, R)$-CHDC was first prepared by reaction of ethyl chloroformate with 1,2-cyclohex4-enediol enantio-enriched (83\% ee) through a resolution using $(S)-(+)$ - $O$-acetyl-mandelic acid (refer to the Experimental section). 

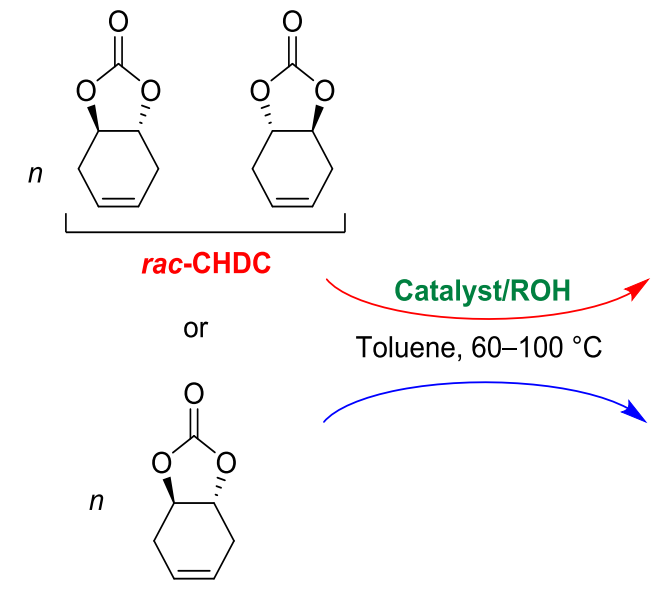

$(R, R)-\mathrm{CHC}$

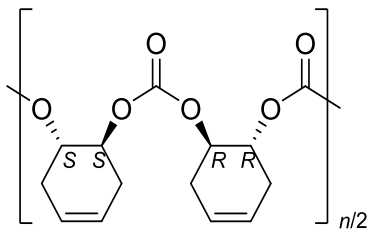

highly syndiotactic PCHDC

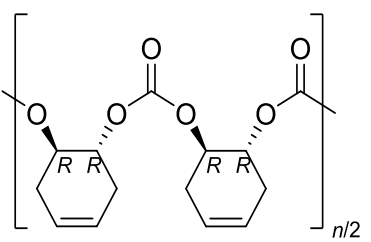

highly isotactic PCHDC

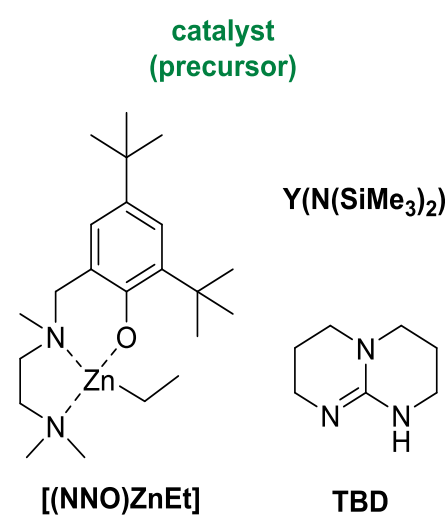

TBD

Scheme 3. ROP of trans-CHDC (racemic or $(R, R)$ ) towards highly isotactic PCHDC

mediated by metal- or organo-based catalyst systems.

Table 1. ROP of trans-CHDC (racemic or $(R, R)$ ) mediated by metal- or organo-based catalyst systems.

\begin{tabular}{ccccccccc}
\hline Entry & Catalyst & $\mathrm{ROH}$ & $\begin{array}{c}{[\mathrm{CHDC}]_{0} /} \\
{[\mathrm{Cat} .]_{0} /[\mathrm{ROH}]_{0}}\end{array}$ & $\begin{array}{c}\text { Temp. } \\
\left({ }^{\circ} \mathrm{C}\right)\end{array}$ & $\begin{array}{c}\text { Time } \\
(\mathrm{h})\end{array}$ & $\begin{array}{c}\text { Conv. }^{\mathrm{c}} \\
(\%)\end{array}$ & $\begin{array}{c}M_{\mathrm{n}, \text { theo }}{ }^{\mathrm{d}} \\
\left(\mathrm{g} . \mathrm{mol}^{-1}\right)\end{array}$ & $\begin{array}{c}M_{\mathrm{n}}^{\mathrm{e}} \\
\left(\mathrm{g}^{\mathrm{mol}} \mathrm{mol}^{-1}\right)\end{array}$ \\
\hline $1^{\mathrm{a}}$ & {$[(\mathrm{NNO}) \mathrm{ZnEt}]$} & $\mathrm{BnOH}$ & $50: 1: 1$ & 60 & 120 & 87 & 6200 & $4000 / 6300$ \\
$2^{\mathrm{a}}$ & {$[(\mathrm{NNO}) Z n E t]$} & $\mathrm{BnOH}$ & $50: 1: 1$ & 80 & 6 & $26^{\mathrm{f}}$ & 1900 & $\mathrm{nd}^{\mathrm{f}}$ \\
$3^{\mathrm{a}}$ & {$[(\mathrm{NNO}) \mathrm{ZnEt}]$} & $\mathrm{BnOH}$ & $100: 1: 1$ & 80 & 120 & 61 & 8600 & 6100 \\
$4^{\mathrm{a}}$ & $\mathrm{TBD}$ & $\mathrm{BnOH}$ & $100: 1: 1$ & 80 & 120 & 37 & 5200 & 3800 \\
$5^{\mathrm{a}}$ & $\mathrm{Y}\left[\mathrm{N}(\mathrm{SiMe})_{2}\right]_{3}$ & $i \mathrm{PrOH}$ & $100: 1: 1$ & 80 & 120 & $5^{\mathrm{f}}$ & 800 & $\mathrm{nd}^{\mathrm{f}}$ \\
$6^{\mathrm{a}}$ & {$[(\mathrm{NNO}) Z n E t]$} & $\mathrm{BnOH}$ & $100: 1: 1$ & 100 & 16 & $21^{\mathrm{f}}$ & 3000 & $\mathrm{nd}^{\mathrm{f}}$ \\
$7^{\mathrm{b}}$ & {$[(\mathrm{NNO}) Z n E t]$} & $\mathrm{BnOH}$ & $50: 1: 1$ & 60 & 72 & 25 & 1900 & $3500^{\mathrm{g}}$ \\
\hline
\end{tabular}

${ }^{\mathrm{a}}$ Trans-racemic monomer. ${ }^{\mathrm{b}}$ Trans- $(R, R)\left(83 \%\right.$ ee) monomer. ${ }^{\mathrm{c}}$ Monomer conversion as determined by ${ }^{1} \mathrm{H}$ NMR analysis of the crude reaction mixture. ${ }^{\mathrm{d}}$ Theoretical molar mass calculated from the relation: $M_{\mathrm{n}, \text { theo }}=\left([\mathrm{CHDC}]_{0} /[\mathrm{ROH}]_{0}\right) \times$ Conversion $_{\mathrm{CHDC}} \times M_{\mathrm{CHDC}}+M_{\mathrm{ROH}}$, with $M_{\mathrm{CHDC}}=140 \mathrm{~g} \cdot \mathrm{mol}^{-1}, M_{\mathrm{BnOH}}=$ $108 \mathrm{~g} \cdot \mathrm{mol}^{-1}$ and $M_{\mathrm{iPrOH}}=60 \mathrm{~g} \cdot \mathrm{mol}^{-1}$. ${ }^{\mathrm{e}} M_{\mathrm{n}, \mathrm{SEC}}$ as determined by $\mathrm{SEC}$ in $\mathrm{CHCl}_{3}$ calibrated $v s$. polystyrene standards with peak mass values of main signals in (multimodal) distribution(s), unless otherwise stated; see the Supporting Information. ${ }^{\mathrm{f}}$ Oily material which could not be isolated. ${ }^{\mathrm{g}} M_{\mathrm{n}, \mathrm{NMR}}$ as determined from terminal groups.

Polymerizations were run in toluene, at high monomer concentration $\left([\mathrm{CHDC}]_{0}=4\right.$ $\mathrm{M}$ ), in the temperature range $60-100{ }^{\circ} \mathrm{C}$ (Table 1). As anticipated from the DFT 
computations, trans-CHDC is significantly less reactive than trans-CHC, whichever the catalyst system used. With $[(\mathrm{NNO}) \mathrm{ZnEt}] / \mathrm{BnOH}$, which proved the most active among the three systems investigated, the reaction proceeded at $60{ }^{\circ} \mathrm{C}$ but required 5 days to convert 43 equiv. (apparent turnover frequency, $\mathrm{TOF}_{\mathrm{app}}=0.36 \mathrm{~h}^{-1}$; entry 1). This is $c a .2$ orders of magnitude lower than for trans-CHC under comparable conditions $\left(\mathrm{TOF}_{\mathrm{app}}=30-150 \mathrm{~h}^{-1}\right) .{ }^{13 \mathrm{a}}$ Raising the temperature to 80 or $100{ }^{\circ} \mathrm{C}$ hardly increased the activity $\left(\mathrm{TOF}_{\mathrm{app}}=0.51 \mathrm{~h}^{-1}\right.$; entry 3 and $\mathrm{TOF}_{\text {app }}=1.3 \mathrm{~h}^{-1}$; entry 6 , respectively). This is most likely due to the proximity to the ceiling temperature of PCHDC. ${ }^{23}$ Although the detailed kinetics were not investigated, the ROP of $(R, R)$-CHDC appeared twice slower than that of the racemic monomer $\left(\mathrm{TOF}_{\mathrm{app}}=0.17\right.$ vs. $0.36 \mathrm{~h}^{-1}$; entries 1 vs. 7). The commercially available, simple organic guanidine TBD catalyst combined with $\mathrm{BnOH}$ showed a lower activity than the zinc system (entry 4); this reactivity trend is in line with the results for trans-CHC. ${ }^{13 a}$ On the other hand, the yttriumbased system showed very poor productivity (entry 5 ).

When poor monomer conversions were reached, such as with the latter sluggish catalyst, only oily materials which could not be isolated were produced. Higher molar mass $\mathrm{P}($ rac-CHDC)s (entries 1,3 and 4$)$ and $\mathrm{P}(R, R-\mathrm{CHDC})$ (entry 7) were isolated as white powders by precipitation from $\mathrm{CH}_{2} \mathrm{Cl}_{2} / \mathrm{MeOH}(1: 15 v / v)$. These polymers are soluble in chlorinated solvents $\left(\mathrm{CH}_{2} \mathrm{Cl}_{2}, \mathrm{CHCl}_{3}\right)$ at room temperature and are insoluble in hydrocarbons (toluene, pentane) and ethers (THF, $\left.\mathrm{Et}_{2} \mathrm{O}\right)$. They were characterized by ${ }^{1} \mathrm{H}$ and ${ }^{13} \mathrm{C} \mathrm{NMR}$ spectroscopy, MALDI-ToF mass spectrometry and DSC analysis.

The MALDI-ToF mass spectrum of a PCHDC prepared with the $[(\mathrm{NNO}) \mathrm{ZnEt}] / \mathrm{BnOH}$ catalytic system showed a single major population of macromolecules with the expected architecture of regular CHDC repeat units with benzyloxy and hydroxy end-groups (Figure 1); no evidence of decarboxylation products was observed. ${ }^{24}$ 


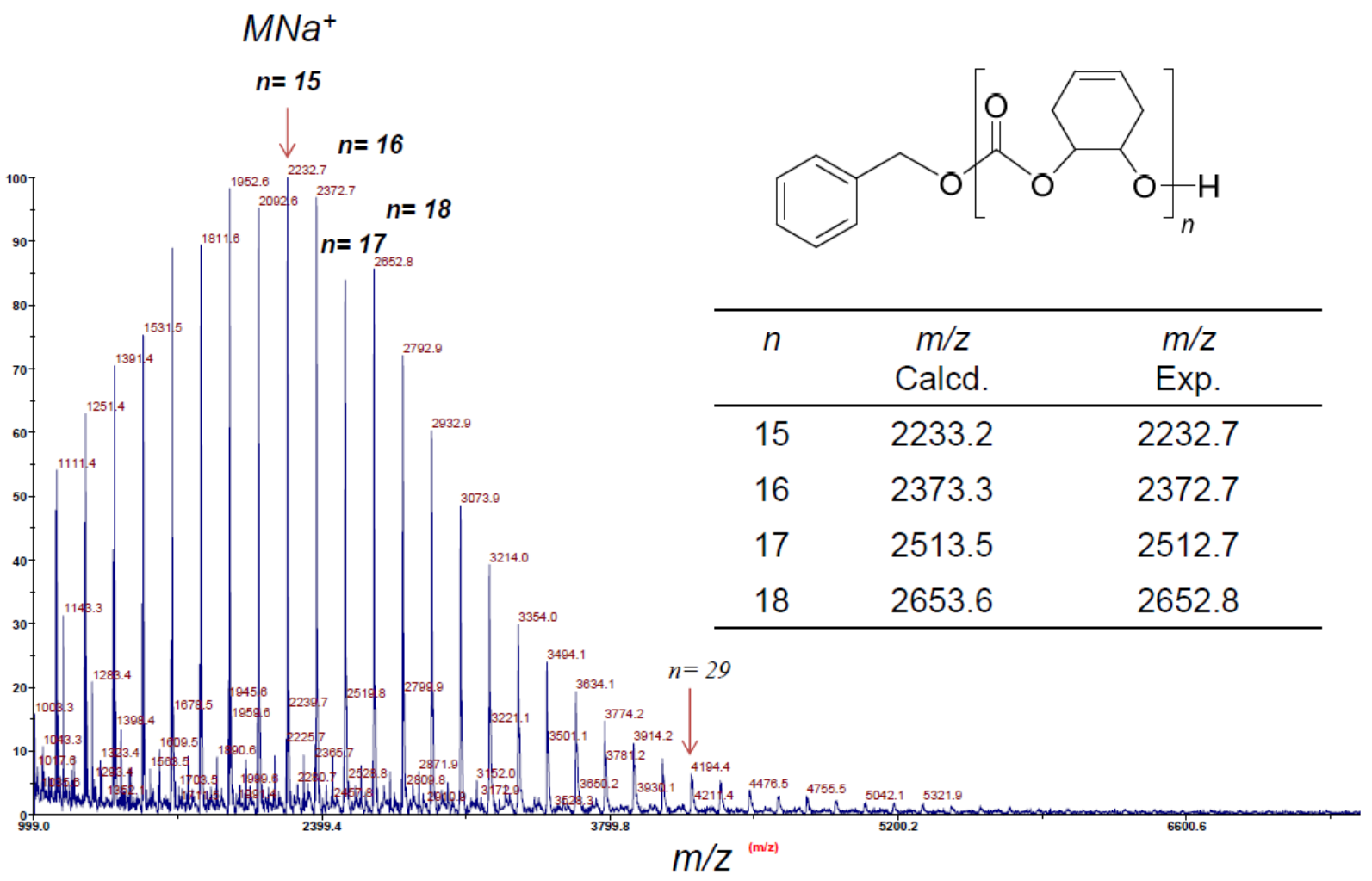

Figure 1. MALDI-ToF mass spectrum of a PCHDC prepared by ROP of trans-rac-CHDC mediated by the $[(\mathrm{NNO}) \mathrm{ZnEt}] / \mathrm{BnOH}$ catalytic system (Table 1, entry 3) (the detected ions and calculated masses correspond to $\left.\left[\mathrm{C}_{6} \mathrm{H}_{5} \mathrm{CH}_{2} \mathrm{O}\left(\mathrm{C}_{7} \mathrm{H}_{8} \mathrm{O}_{3}\right)_{n} \mathrm{H}\right] \cdot \mathrm{Na}^{+}\right)$.

The ${ }^{1} \mathrm{H}$ NMR spectra of $\mathrm{P}($ rac-CHDC $)$ and $\mathrm{P}(R, R$-CHDC $)$, synthesized by ROP of trans-rac-CHDC and trans-( $R, R)-\mathrm{CHDC}$, respectively, in the presence of [(NNO)ZnEt] / $\mathrm{BnOH}$ or $\mathrm{TBD} / \mathrm{BnOH}$ catalyst systems, showed the expected signals corresponding to the main chain olefinic, methine and methylene hydrogens (Figures S6, S8 and S10). No other signals which may reflect partial decarboxylation or other side processes could be noticed. For low molecular samples, the signals for the terminal benzyloxy group could generally ${ }^{25}$ be observed (see e.g. Figures $\mathrm{S} 10, \mathrm{~S} 11$ ), in agreement with the mass spectrometry results (vide supra). Also, the backbone signals in the three spectra are equally sharp, suggesting a welldefined microstructure in all samples. 
Detailed microstructural analysis of the recovered PCHDCs was performed by ${ }^{13} \mathrm{C}\left\{{ }^{1} \mathrm{H}\right\}$ NMR spectroscopy (Figures 2 and S7, S9, S11 and S13). For comparison purposes, we also prepared a PCHD by copolymerization of $\mathrm{CHDO}$ and $\mathrm{CO}_{2}$ in the presence of a catalyst which is known to provide slightly syndiotactic $\mathrm{PCHCs}$ from $\mathrm{CHO}$ and $\mathrm{CO}_{2}$, that is rac-(Salen)CoBr (Scheme 4). ${ }^{15 a, 26}$ The carbonyl region of the NMR spectra is indicative of the tacticity of the PCHDCs. The polymer recovered from ROP of trans-(R,R)-CHDC features a unique sharp resonance at $\delta 154.0 \mathrm{ppm}$ assigned to pure isotactic PCHDC (Figures 2c and S11). This signal is also observed as the less intense one in the ${ }^{13} \mathrm{C}\left\{{ }^{1} \mathrm{H}\right\}$ NMR spectrum of the PCHDC prepared via ROCOP of $\mathrm{CHDO}$ and $\mathrm{CO}_{2}$ with rac-(Salen) $\mathrm{CoBr}$, in addition to a major, broad signal centered at $\delta 153.6 \mathrm{ppm}$, assigned to the syndiotactic sequences ( $\mathrm{rr}$, likely overlapping with $m r$ ) (Figures $2 \mathrm{~d}$ and S13). Most interestingly, the latter resonance at $\delta 153.6$ ppm is the only one observed, but then as a quite sharp signal, in the spectra of the PCHDCs prepared from trans-rac-CHDC, either with the $[(\mathrm{NNO}) \mathrm{ZnEt}] / \mathrm{BnOH}$ or $\mathrm{TBD} / \mathrm{BnOH}$ catalyst systems (Figures 2a,b). This indicates that these polymers are highly syndiotactic PCHDCs. This is in striking contrast with the ROP of trans-rac-CHC which provided with the same catalyst systems PCHCs with $64-76 \%$ isoselectivity. ${ }^{13 a}$ The high syndioselectivity implies a type of "enantiomer-differentiating polymerization". Its origin is still unclear but the striking difference observed between the behavior of $r a c-C H D C$ and that of $r a c-C H C$ indicates that there are subtle effects imparted by the six-membered ring fused with the 5-membered cyclocarbonate. 


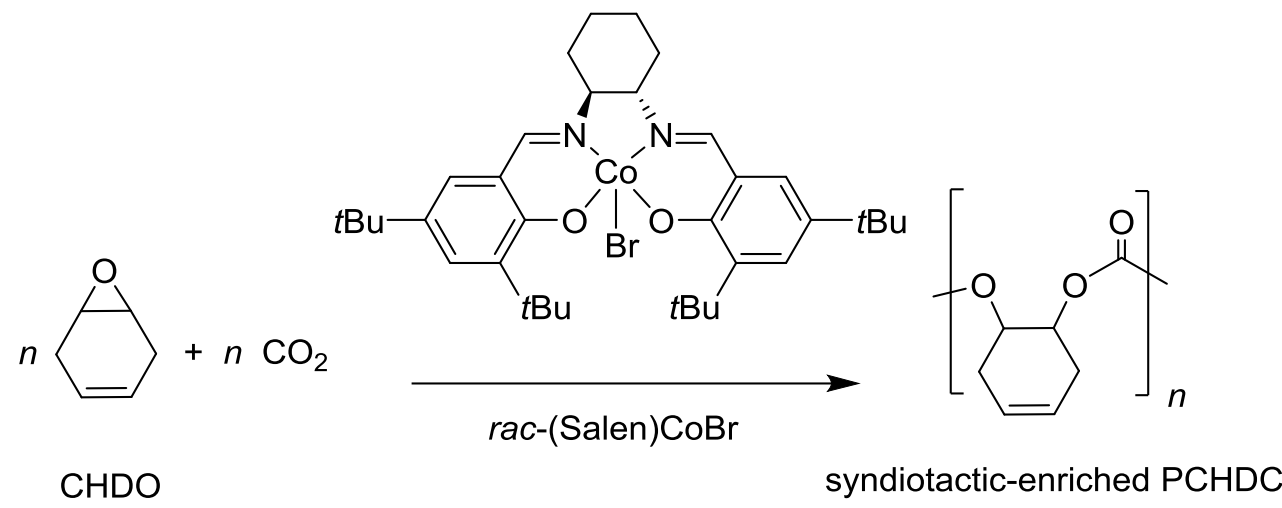

Scheme 4. Preparation of slightly syndiotactic-enriched PCHDC via ROCOP of $\mathrm{CHDO} / \mathrm{CO}_{2} \cdot{ }^{15 \mathrm{a}}$

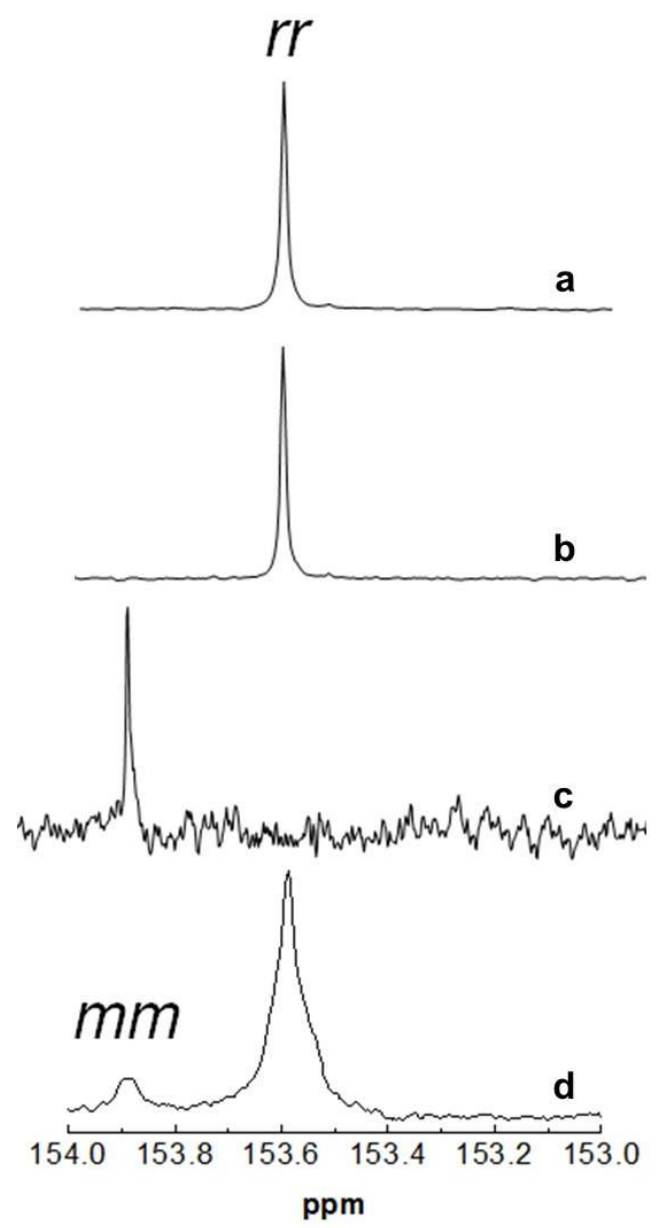

Figure 2. Detail of the carbonyl region of the ${ }^{13} \mathrm{C}\left\{{ }^{1} \mathrm{H}\right\}$ NMR spectra $\left(100 \mathrm{MHz}, \mathrm{CDCl}_{3}\right.$, $23{ }^{\circ} \mathrm{C}$ ) of PCHDCs synthesized by: [a] ROP of trans-rac-CHDC with [(NNO)ZnEt]/BnOH (Table 1, entry 3), [b] ROP of trans-rac-CHDC with TBD/BnOH (Table 1, entry 4), [c] ROP 
of trans- $(R, R)-\mathrm{CHDC}$ with $[(\mathrm{NNO}) \mathrm{ZnEt}] / \mathrm{BnOH}$ (Table 1, entry 7$)$, and [d] ROCOP of $\mathrm{CHDO} / \mathrm{CO}_{2}$ with $\mathrm{rac}$-(Salen)CoBr.

The PCHDCs which could be recovered as solids were analyzed by SEC in $\mathrm{CHCl}_{3}$ (as they are completely insoluble in THF). These analyses proved however erratic as the polymers were not always eluted, and the few chromatograms obtained often appeared bi/multimodal (Figures S14 and S15) for reasons we could not explain, possibly linked to the difficult elution and/or absorption of PCHDC on the columns. Similar problems were encountered previously with highly syndiotactic poly(3-hydroxybutyrate)s; ${ }^{27}$ note that PCHDCs obtained by ROCOP of CHDO with $\mathrm{CO}_{2}$, which are just slightly syndiotacticenriched (Figure 2d) could be analyzed by SEC in THF. ${ }^{15}$ Nevertheless, the SEC molar masses thus determined were roughly in agreement with the calculated ones. We assume that these SEC results do not reflect the real control achieved in the ROP of CHDC, as further evidenced by convincing SEC data obtained on CHDC copolymers (vide infra).

The thermal characteristics of syndiotactic PCHDCs prepared from rac-CHDC were determined by DSC (Figure 3). Independently of the catalyst used for their preparation $([(\mathrm{NNO}) \mathrm{ZnEt}] / \mathrm{BnOH}$ or $\mathrm{TBD} / \mathrm{BnOH})$, these materials featured a crystallization at $T_{\mathrm{c}}=c a$. $267{ }^{\circ} \mathrm{C}$ and a melting transition at $T_{\mathrm{m}}=\mathrm{ca} .318^{\circ} \mathrm{C}$; however, they already start to decompose at this temperature (Figure 3). ${ }^{28}$ Slightly syndiotactic PCHDCs produced via ROCOP of $\mathrm{CHDO}$ and $\mathrm{CO}_{2}$ exhibited no melting transition, only a glass transition at $T_{\mathrm{g}}=115-123{ }^{\circ} \mathrm{C} .{ }^{15}$ This glass transition was not clearly observed in the syndiotactic PCHDCs prepared by ROP of rac-CHDC. 


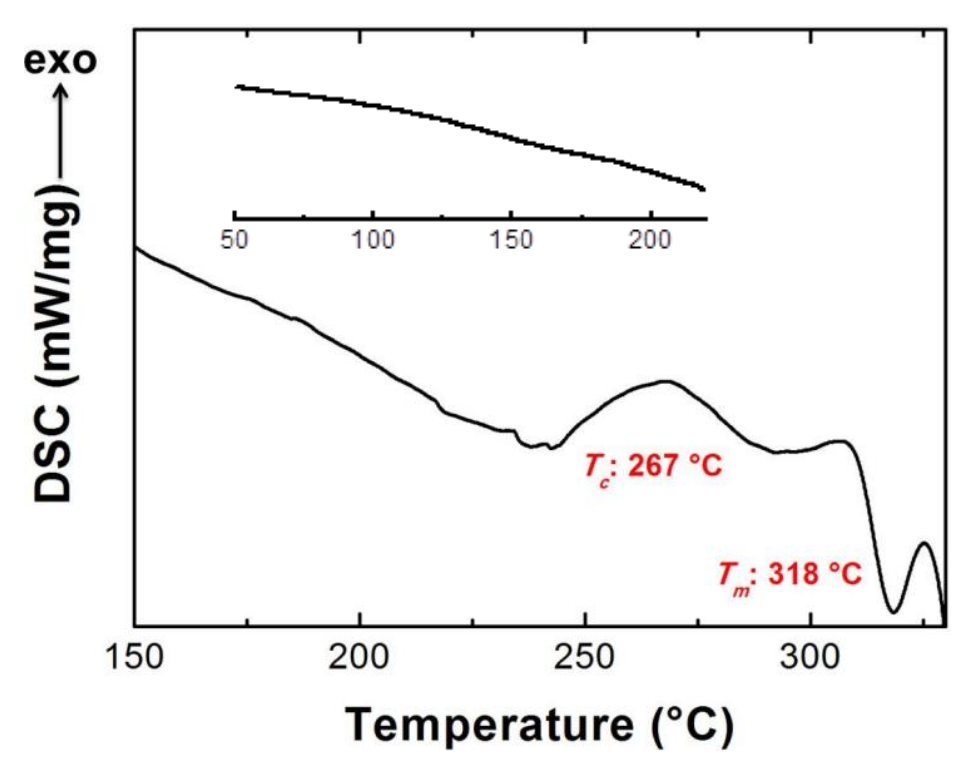

Figure 3. DSC thermogram (first heating cycle; heating rate $=10^{\circ} \mathrm{C} \cdot \mathrm{min}^{-1}$; argon flow) of a PCHDC prepared from the ROP of trans-racemic-CHDC (Table 1, entry 3).

Copolymerization of rac-CHDC. In order to explore the ability of rac-CHDC to copolymerize and eventually characterize the resulting materials, both simultaneous and sequential copolymerizations were attempted. Two cyclic ester comonomers were selected for this purpose: trans-cyclohexene carbonate $(\mathrm{rac}-\mathrm{CHC})$, for its obvious relationship with racCHDC, and $L$-lactide ( $L$-LA), a monomer of topical interest.

Simultaneous Copolymerizations of rac-CHC and rac-CHDC: Preparation of Random $P(C H C$-co-CHDC $)$ Copolymers. The simultaneous copolymerization of rac-CHC and rac$\mathrm{CHDC}$ was performed in toluene at $100{ }^{\circ} \mathrm{C}$ with the $[(\mathrm{NNO}) \mathrm{ZnEt}] / \mathrm{BnOH}$ system (Scheme 5, Table 2). Rac-CHDC proved to be less reactive than rac-CHC, in line with the results of the DFT computations and homopolymerization experiments. The resulting $\mathrm{P}(\mathrm{CHC}-\mathrm{co}-\mathrm{CHDC})$ copolymers are insoluble in methanol but quite soluble in $\mathrm{THF}, \mathrm{CHCl}_{3}, \mathrm{CH}_{2} \mathrm{Cl}_{2}$ and were readily analyzed by SEC in THF. In contrast to the erratic SEC analyses of PCHDC homopolymers run in $\mathrm{CHCl}_{3}$, the $\mathrm{P}(\mathrm{CHC}-\mathrm{co}$-CHDC) copolymers all featured a monomodal 
and symmetric trace (Figure S16). The number-average molar masses determined $v s$. polystyrene standards (uncorrected for a possible difference in hydrodynamic radii) were close to the theoretical values and the dispersity remained quite narrow, even after $16 \mathrm{~h}$ of reaction at this temperature (Table 2).

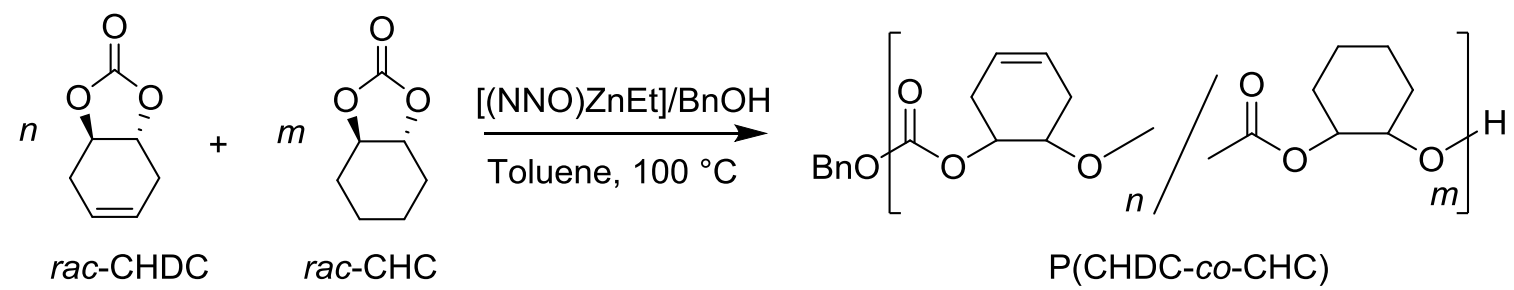

Scheme 5. Simultaneous copolymerization of rac-CHDC and rac-CHC

Table 2. Simultaneous copolymerization of rac-CHDC and rac-CHC mediated by $[(\mathrm{NNO}) \mathrm{ZnEt}] / \mathrm{BnOH}$ systems in toluene at $100{ }^{\circ} \mathrm{C}$.

\begin{tabular}{ccccccccc}
\hline Entry & $\begin{array}{c}{[\mathrm{CHDC}]_{0} /[\mathrm{CHC}]_{0} /} \\
{[\mathrm{Zn}]_{0} /[\mathrm{BnOH}]_{0}}\end{array}$ & $\begin{array}{c}\text { Time } \\
(\mathrm{h})\end{array}$ & $\begin{array}{c}\text { rac-CHDC } \\
\text { Conv. }^{\mathrm{a}}(\%)\end{array}$ & $\begin{array}{c}\text { rac-CHC }_{\mathrm{Conv}^{\mathrm{a}}(\%)} \\
\left(\mathrm{g} \cdot \mathrm{mol}^{-1}\right)\end{array}$ & $\begin{array}{c}M_{\mathrm{n}, \mathrm{theo}}{ }^{\mathrm{b}} \\
\left(\mathrm{g} \cdot \mathrm{mol}^{-1}\right)\end{array}$ & $\begin{array}{c}M_{\mathrm{n}, \mathrm{NMR}}{ }^{\mathrm{c}} \\
\left(\mathrm{g} \cdot \mathrm{mol}^{-1}\right)\end{array}$ & $\begin{array}{c}M_{\mathrm{n}, \mathrm{SEC}}{ }^{\mathrm{d}} \\
D_{\mathrm{M}}\end{array}$ \\
\hline 1 & $50: 50: 1: 1$ & 3 & 38 & 66 & 7500 & 7200 & 5000 & 1.12 \\
2 & $50: 50: 1: 1$ & 16 & 50 & 85 & 9600 & 11000 & 8400 & 1.18 \\
\hline
\end{tabular}

${ }^{a}$ Calculated from the ${ }^{1} \mathrm{H}$ NMR of the crude product. ${ }^{\mathrm{b}}$ Theoretical molar mass value of $\mathrm{P}(\mathrm{CHDC}-\mathrm{co}$-CHC) calculated from the relation: $M_{\text {n,theo }}=M_{\mathrm{CHDC}} \times[\mathrm{CHDC}]_{0} /[\mathrm{BnOH}]_{0} \times$ conv. $(\mathrm{CHDC})+M_{\mathrm{CHC}} \times[\mathrm{CHC}]_{0} /[\mathrm{BnOH}]_{0} \times$ conv. $(\mathrm{CHC})+M_{\mathrm{BnOH}}$, with $M_{\mathrm{CHDC}}=140 \mathrm{~g} \cdot \mathrm{mol}^{-1}, M_{\mathrm{CHC}}=142 \mathrm{~g} \cdot \mathrm{mol}^{-1}, M_{\mathrm{BnOH}}=108 \mathrm{~g} \cdot \mathrm{mol}^{-1} \cdot{ }^{\mathrm{c}} \mathrm{NMR}$ molar mass of the copolymer calculated from the integral value ratio of the signals of $\mathrm{OBn}$ end-group hydrogens to methine/methylene hydrogens of the monomers. ${ }^{\mathrm{d}}$ Experimental number average molar mass (uncorrected) and dispersity values determined by SEC in THF at $30^{\circ} \mathrm{C}$ using polystyrene standards.

The ${ }^{1} \mathrm{H}$ NMR spectra of $\mathrm{P}(\mathrm{CHC}-\mathrm{co}$-CHDC $)$ copolymers show readily distinguishable signals for PCHC and PCHDC units, notably those corresponding to the main chain methine hydrogens at $\delta 4.63$ and $4.93 \mathrm{ppm}$, respectively, and the olefinic hydrogens of PCHDC at $\delta$ 5.56 ppm (Figure 4). No signal that could reflect decarboxylation was observed. Besides, the signals of the benzyloxy end-groups were clearly identified at $\delta 5.13$ and $7.35 \mathrm{ppm}$. This enabled to determine the molar masses by NMR, which were found in good agreement with 
the SEC and theoretical values (Table 2). The carbonyl region of the ${ }^{13} \mathrm{C}\left\{{ }^{1} \mathrm{H}\right\}$ NMR spectrum showed several broadened signals at $\delta$ 153.4-153.9 ppm (Figure 5), suggesting a random enchainment of CHDC and CHC units (Figure 5).

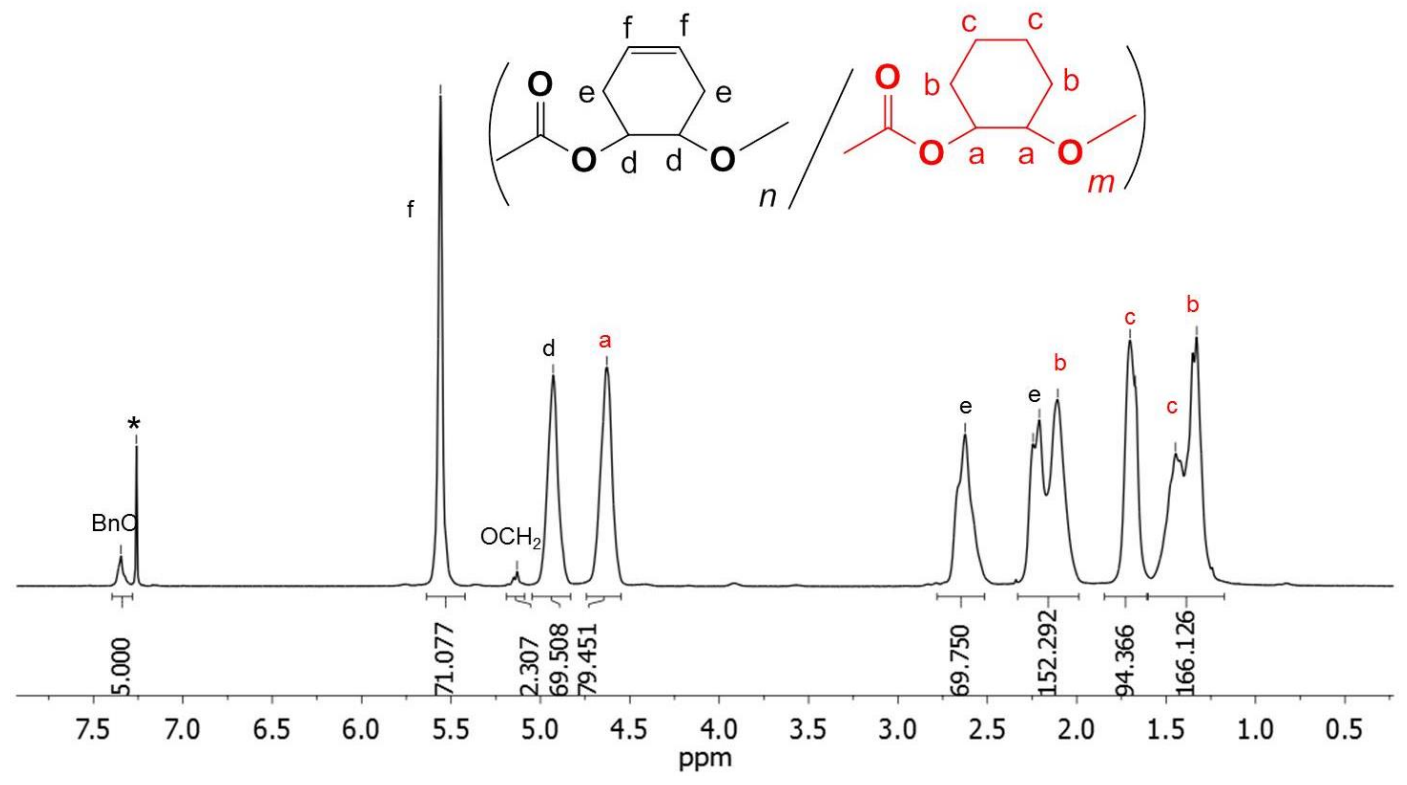

Figure 4. ${ }^{1} \mathrm{H}$ NMR spectrum (400 $\left.\mathrm{MHz}, \mathrm{CDCl}_{3}, 23{ }^{\circ} \mathrm{C}\right)$ of a $\mathrm{P}(\mathrm{CHDC}-\mathrm{co}-\mathrm{CHC})$ prepared by ROP of rac-CHDC and rac-CHC with the [(NNO)ZnEt]/BnOH system (Table 2, entry 2) (* stands for residual $\mathrm{CHCl}_{3}$ resonances). 


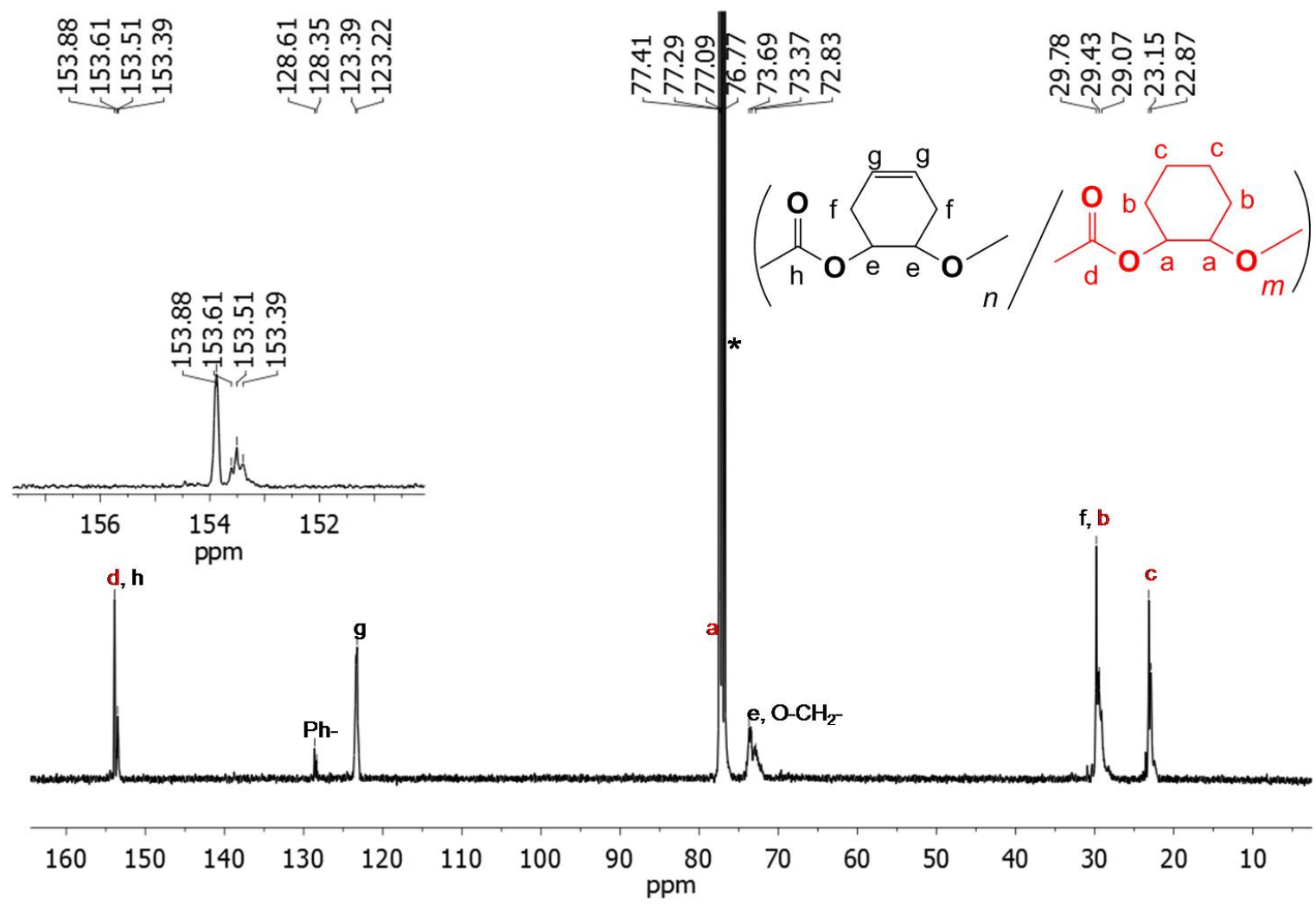

Figure 5. ${ }^{13} \mathrm{C}\left\{{ }^{1} \mathrm{H}\right\}$ NMR spectrum (100 MHz, $\left.\mathrm{CDCl}_{3}, 23{ }^{\circ} \mathrm{C}\right)$ of a $\mathrm{P}(\mathrm{CHC}-$ co-CHDC $)$ prepared by ROP of $r a c-\mathrm{CHC}$ and $r a c-\mathrm{CHDC}$ with the [(NNO)ZnEt]/BnOH system (Table 2, entry 2) (* stands for residual $\mathrm{CHCl}_{3}$ resonances).

The DSC trace (Figure S17) of these $\mathrm{P}(\mathrm{CHDC}-\mathrm{co}-\mathrm{CHC}$ ) copolymers showed a single glass transition at $T_{g}=102{ }^{\circ} \mathrm{C}$. This value is lower than that reported for PCHDC and PCHC homopolymers $\left(T_{g}=c a \cdot 115-123{ }^{\circ} \mathrm{C}^{15}\right.$ and $121^{\circ} \mathrm{C},{ }^{13}$ respectively $)$, but similar to that observed in polycarbonates derived from the terpolymerization of $\mathrm{CHO}, \mathrm{CHDO}$ and $\mathrm{CO}_{2} .{ }^{15 \mathrm{a}}$ No melting transition was detected, which is consistent with the above mentioned random rather than blocky structure of these copolymers.

Sequential Copolymerization of rac-CHC and rac-CHDC: Preparation of Block $P(C H C-b-C H D C)$ Copolymers. The preparation of a diblock $\mathrm{P}(\mathrm{CHC}-b-\mathrm{PCHDC})$ copolymer 
was attempted via the sequential polymerization of $r a c$-CHC followed by that of rac-CHDC in the presence of $[(\mathrm{NNO}) \mathrm{ZnEt}] / \mathrm{BnOH}$ system at $60{ }^{\circ} \mathrm{C}$ in toluene (Scheme 6; Table 3). The reaction proceeded with almost complete conversion of rac-CHC and $c a$. $50 \%$ conversion of rac-CHDC; even though this would lead to a larger conversion of rac-CHDC, the reaction time for the second stage was not further extended to avoid side processes (transcarbonatation, etc). Thanks to the ${ }^{1} \mathrm{H}$ NMR signals of the benzyloxy end-groups $(\delta 5.06$ and $7.28 \mathrm{ppm}$ ), the molar mass could be monitored and was shown to increase expectedly from the first $\left(M_{\mathrm{n}, \mathrm{NMR}}=6600 \mathrm{~g} \cdot \mathrm{mol}^{-1}\right)$ to the second block $\left(M_{\mathrm{n}, \mathrm{NMR}}=10800 \mathrm{~g} \cdot \mathrm{mol}^{-1}\right) . \mathrm{In}$ fact, the ${ }^{1} \mathrm{H}$ and ${ }^{13} \mathrm{C}$ NMR spectra of this copolymer (Figures S18 and S19), isolated after precipitation in methanol, resemble much that of the random copolymer obtained by simultaneous copolymerization (vide supra). However, the materials could be differentiated by their thermal properties. The DSC trace of the $\mathrm{P}(\mathrm{CHC}-b$-PCHDC $)$ copolymer features, in addition to a glass transition at $T_{\mathrm{g}}=109^{\circ} \mathrm{C}$ similar to that of the random copolymer, a melting transition at $T_{\mathrm{m}}=262{ }^{\circ} \mathrm{C}\left(\Delta H_{\mathrm{m}}=22.1 \mathrm{~J}_{\mathrm{g}}{ }^{-1}\right)$ assignable to the syndiotactic PCHDC block (Figure S20).<smiles>O=C1OC2CCCCC2O1</smiles>
rac-CHC

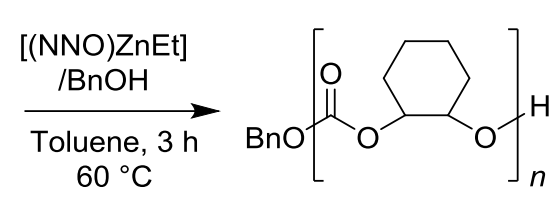

$\mathrm{PCHC}$

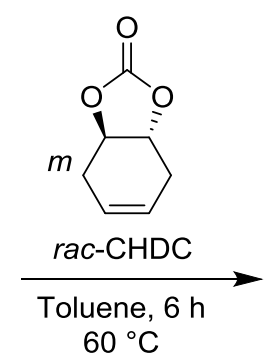
$60{ }^{\circ} \mathrm{C}$



$\mathrm{P}(\mathrm{CHC}-b-\mathrm{CHDC})$

Scheme 6. Sequential copolymerization of $r a c$-CHC followed by rac-CHDC.

Table 3. Sequential copolymerization of rac-CHC followed by rac-CHDC mediated by the $[(\mathrm{NNO}) \mathrm{ZnEt}] / \mathrm{BnOH}$ system at $60{ }^{\circ} \mathrm{C}$ (Scheme 6). 


\begin{tabular}{|c|c|c|c|c|c|c|c|c|c|}
\hline & & & & \multicolumn{2}{|c|}{ PCHC } & \multicolumn{4}{|c|}{ PCHC- $b$-PCHDC } \\
\hline Entry & $\begin{array}{c}{[\mathrm{rac}-\mathrm{CHC}]_{0} /} \\
{[\mathrm{rac}-\mathrm{CHDC}]_{0} /} \\
{[\mathrm{Zn}]_{0} /[\mathrm{BnOH}]_{0}}\end{array}$ & $\begin{array}{c}\text { CHC } \\
\text { Conv. }^{\mathrm{a}} \\
(\%)\end{array}$ & $\begin{array}{c}\text { CHDC } \\
\text { Conv. }^{\mathrm{a}} \\
(\%)\end{array}$ & $\begin{array}{c}M_{\mathrm{n}, \text { theo }}{ }^{\mathrm{b}} \\
\left(\mathrm{g} \cdot \mathrm{mol}^{-1}\right)\end{array}$ & $\begin{array}{c}M_{\mathrm{n}, \mathrm{NMR}}^{\mathrm{c}} \\
\left(\mathrm{g} \cdot \mathrm{mol}^{-1}\right)\end{array}$ & $\begin{array}{c}M_{\mathrm{n}, \text { theo }}{ }^{\mathrm{d}} \\
\left(\mathrm{g} \cdot \mathrm{mol}^{-1}\right)\end{array}$ & $\begin{array}{c}M_{\mathrm{n}, \mathrm{NMR}}^{\mathrm{c}} \\
\left(\mathrm{g} \cdot \mathrm{mol}^{-1}\right)\end{array}$ & $\begin{array}{c}M_{\mathrm{n}, \mathrm{SEC}}{ }^{\mathrm{e}} \\
\left(\mathrm{g} \cdot \mathrm{mol}^{-1}\right)\end{array}$ & $\emptyset_{\mathrm{M}}^{\mathrm{e}}$ \\
\hline 1 & $50: 50: 1: 1$ & 95 & 53 & 6800 & 6600 & 10600 & 10800 & 9800 & 1.22 \\
\hline
\end{tabular}

${ }^{a}$ Calculated from the ${ }^{1} \mathrm{H}$ NMR of the crude product at the intermediary and final stages. ${ }^{\mathrm{b}}$ Theoretical molar mass calculated from the relation: $M_{\mathrm{n} \text {,theo }}=\left([\mathrm{CHC}]_{0} /[\mathrm{BnOH}]_{0}\right) \times$ Conv.CHC $\times M_{\mathrm{CHC}}+M_{\mathrm{BnOH}}$, with $M_{\mathrm{CHC}}=142 \mathrm{~g} \cdot \mathrm{mol}^{-1}$ and $M_{\mathrm{BnOH}}=108$ g.mol ${ }^{-1} \cdot{ }^{c}$ NMR molar mass of the copolymer calculated from the integral value ratio of the signals of OBn end-group hydrogens to methine / methylene hydrogens of the monomers. ${ }^{\mathrm{d}}$ Theoretical molar mass value of $\mathrm{P}$ (CHC-co-CHDC) calculated from the relation: $M_{\mathrm{n} \text {, theo }}=M_{\mathrm{CHC}} \times[\mathrm{CHC}]_{0} /[\mathrm{BnOH}]_{0} \times$ conv. $\mathrm{CHC}+M_{\mathrm{CHDC}} \times[\mathrm{CHDC}]_{0} /[\mathrm{BnOH}]_{0} \times$ conv.CHDC + $M_{\mathrm{BnOH}}$, with $M_{\mathrm{CHDC}}=140 \mathrm{~g} \cdot \mathrm{mol}^{-1}$. ${ }^{\mathrm{e}}$ Experimental number average molar mass (uncorrected) and dispersity values determined by SEC in THF at $30^{\circ} \mathrm{C}$ using polystyrene standards.

Simultaneous Copolymerization of rac-CHDC and L-LA: Preparation of Random $P(C H D C$-co-LLA) Copolymers. Random copolymerizations of rac-CHDC and L-LA in various ratios were carried out with the $[(\mathrm{NNO}) \mathrm{ZnEt}] / \mathrm{BnOH}$ system at $80{ }^{\circ} \mathrm{C}$ in toluene (Scheme 7, Table 4). Figure 6 shows the representative SEC trace of a P(CHDC-co-LLA) copolymer with a $M_{\mathrm{n}, \mathrm{SEC}}$ of $17100 \mathrm{~g} \cdot \mathrm{mol}^{-1}$ and a dispersity of 1.39 (Table 4, entry 2). The monomodal, symmetric SEC trace reveals that both monomers copolymerize quite effectively, although monitoring of monomers' conversion indicate that, as anticipated, $L$-LA is much more reactive than rac-CHDC.

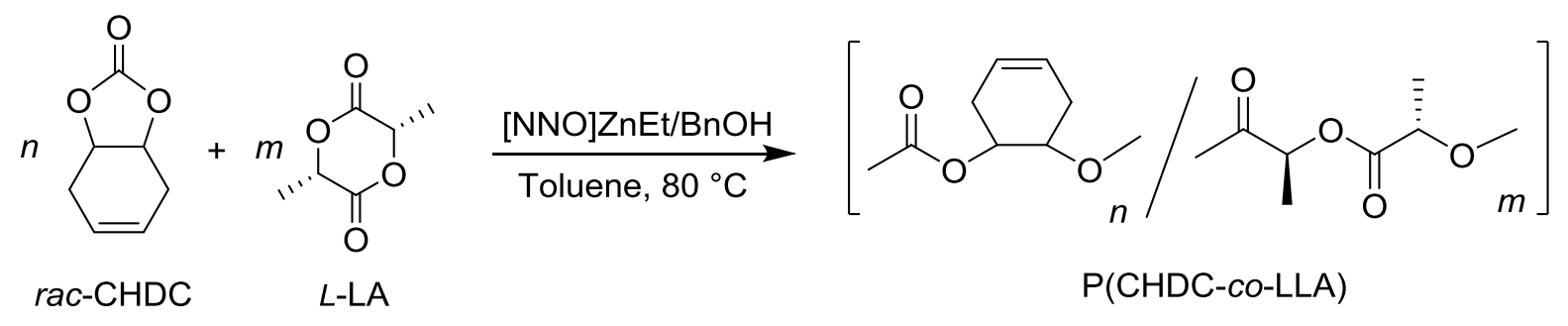

Scheme 7. Simultaneous copolymerization of rac-CHDC and $L$-LA

Table 4. Simultaneous copolymerization of rac-CHDC and $L$-LA mediated by the $[(\mathrm{NNO}) \mathrm{ZnEt}] / \mathrm{BnOH}$ system at $80{ }^{\circ} \mathrm{C}$. 


\begin{tabular}{cccccccccc}
\hline Entry & $\begin{array}{c}{[\mathrm{rac}-\mathrm{CHDC}]_{0} /} \\
{[L-\mathrm{LA}]_{0} /}\end{array}$ & $\begin{array}{c}\text { Time } \\
(\mathrm{h})\end{array}$ & $\begin{array}{c}\text { rac-CHDC } \\
\mathrm{Conv}^{\mathrm{a}}\end{array}$ & $\begin{array}{c}L \text {-LA } \\
\text { Conv. }^{\mathrm{a}}\end{array}$ & $\begin{array}{c}M_{\mathrm{n}, \text { theo }}{ }^{\mathrm{b}} \\
\left(\mathrm{g} \cdot \mathrm{mol}^{-1}\right)\end{array}$ & $\begin{array}{c}M_{\mathrm{n}, \mathrm{NMR}}{ }^{\mathrm{c}} \\
\left(\mathrm{g} \cdot \mathrm{mol}^{-1}\right)\end{array}$ & $\begin{array}{c}M_{\mathrm{n}, \mathrm{SEC}}{ }^{\mathrm{d}} \\
\left(\mathrm{g} \cdot \mathrm{mol}^{-1}\right)\end{array}$ & $\begin{array}{c}\bigoplus_{\mathrm{M}} \\
(\%)\end{array}$ & $\begin{array}{c}T_{\mathrm{g}} \\
\left({ }^{\circ} \mathrm{C}\right)\end{array}$ \\
\hline 1 & $50: 150: 1: 1$ & 6 & 77 & 100 & 27100 & 23200 & 8800 & 1.35 & $\mathrm{nd}$ \\
2 & $100: 100: 1: 1$ & 24 & 74 & 100 & 24900 & 18600 & 17100 & 1.39 & 74 \\
3 & $150: 50: 1: 1$ & 6 & 56 & 100 & 19100 & 17400 & 6300 & 1.43 & 87 \\
\hline
\end{tabular}

${ }^{a}$ Calculated from the ${ }^{1} \mathrm{H}$ NMR of the crude product. ${ }^{\mathrm{b}}$ Theoretical molar mass value of P(CHDC-co-LLA) calculated from the relation: $M_{\mathrm{n} \text {,theo }}=M_{\text {rac }-\mathrm{CHDC}} \times[\mathrm{rac}-\mathrm{CHDC}]_{0} /[\mathrm{BnOH}]_{0} \times$ conv.rac -CHDC $+M_{\mathrm{LLA}} \times[\mathrm{LLA}]_{0} /[\mathrm{BnOH}]_{0} \times$ conv.LLA $+M_{\mathrm{BnOH}}$ with $M_{\text {rac }-\mathrm{CHDC}}=140 \mathrm{~g} \cdot \mathrm{mol}^{-1}, M_{\mathrm{LLA}}=144 \mathrm{~g} \cdot \mathrm{mol}^{-1}$, and $M_{\mathrm{BnOH}}=108 \mathrm{~g} \cdot \mathrm{mol}^{-1} \cdot{ }^{\mathrm{c}} \mathrm{NMR}$ molar mass value of P(CHDC-co-LLA) calculated from the integral value ratio of the signals of $\mathrm{OBn}$ end-group hydrogens to internal methine or methylene hydrogens. ${ }^{\mathrm{d}}$ Experimental number average molar mass (uncorrected) and dispersity values determined by SEC in THF at $30{ }^{\circ} \mathrm{C}$ using polystyrene standards. ${ }^{\mathrm{e}}$ Glass transition temperature determined by DSC $\left(2^{\text {nd }}\right.$ heating cycle, $\left.10{ }^{\circ} \mathrm{C} \cdot \mathrm{min}^{-1}\right)$.

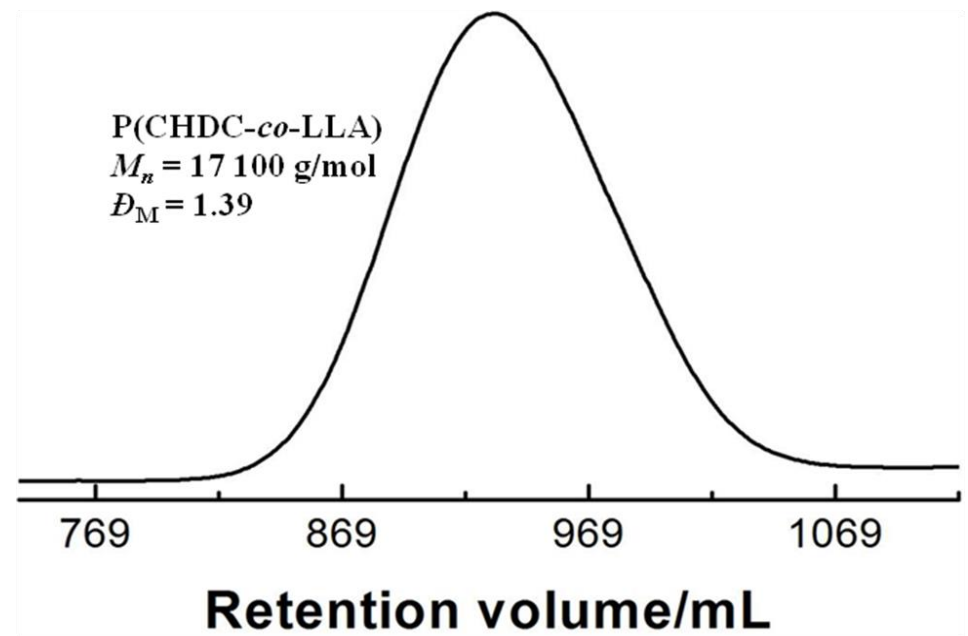

Figure 6. SEC trace $\left(\mathrm{THF}, 30^{\circ} \mathrm{C}\right)$ of a $\mathrm{P}(\mathrm{CHDC}-\mathrm{co}$-LLA) prepared by simultaneous copolymerization of rac-CHDC and $L$-LA with the [(NNO)ZnEt]/BnOH system (Table 4, entry 2).

The ${ }^{1} \mathrm{H}$ and ${ }^{13} \mathrm{C}\left\{{ }^{1} \mathrm{H}\right\}$ NMR spectra of these P(CHDC-co-LLA) copolymers show the expected signals for the two monomers (Figures S21 and S22). The ${ }^{1} \mathrm{H}$ signals for the phenyl hydrogens of the benzyloxy end-groups can be discerned and then used to determine the molar mass. The $M_{\mathrm{n}, \mathrm{NMR}}$ values thus determined agreed well with the theoretical $M_{\mathrm{n}, \text { theo }}$ ones. The (uncorrected) $M_{\mathrm{n}, \mathrm{SEC}}$ values differ much according to the relative amount of CHDC-LLA units, suggesting quite different hydrodynamic volumes. 
The DSC traces of the copolymers feature only a glass transition; no melting transition was observed. The copolymers with a significant fraction of CHDC have a higher $T_{\mathrm{g}}\left(74{ }^{\circ} \mathrm{C}\right.$, entry 2; $87{ }^{\circ} \mathrm{C}$, entry 3; Figures S23 and S24) than that of the PLLA homopolymer ( $c a$. $\left.60-65^{\circ} \mathrm{C}\right)$.

\section{Conclusions}

We have shown for the first time that trans-cyclohexadiene carbonate (CHDC) can be polymerized with regular ROP catalyst systems made of a zinc-based complex or a guanidine, associated with an alcohol. As anticipated by DFT computations, its reactivity is however significantly lower than that of trans-cyclohexene carbonate (CHC). This is exemplified both in homopolymerizations of CHDC and copolymerizations of CHDC with CHC and L-LA. The $[(\mathrm{NNO}) \mathrm{ZnEt}] / \mathrm{BnOH}$ system proved to be a more active catalyst than TBD for these ROP reactions, which proceeded without decarboxylation. Quite interestingly, even though no chiral catalyst was used, ROP of rac-CHDC proceeded in a stereoselective fashion: highly syndiotactic PCHDC was obtained with both the zinc and TBD-based catalysts, as revealed by ${ }^{13} \mathrm{C}$ NMR studies. ROP of rac-CHDC thus provides a new entry toward engineering polycarbonates that is much complementary to ROCOP of cyclohexadiene oxide with $\mathrm{CO}_{2}$. Indeed, the latter route thus far only yielded atactic or slightly syndiotactic PCHDC. ${ }^{15}$ The high syndioselectivity observed in the ROP of rac-CHDC contrasts with the modest isoselectivity $\left(P_{\mathrm{m}}=c a .75 \%\right)$ for the ROP of $r a c-\mathrm{CHC}$ with the same catalyst systems. ${ }^{13 a}$ This evidences subtle effects induced by the adjacent ring fused to the 5-membered cyclocarbonate moiety. 


\section{Acknowledgements}

Financial support of this research (Post-Doctoral grant to A.K.D.) from Total Raffinage Chimie is gratefully acknowledged.

Supporting information includes NMR, SEC and DSC data for monomer and polymers. This information is available free of charge via the Internet.

\section{References and Notes}

1 (a) D. J. Darensbourg and S. J. Wilson, Macromolecules, 2013, 46, 5929-5934; (b) Y. Liu, W.-M. Ren, J. Liu and X.-B. Lu, Angew. Chem., Int. Ed., 2013, 52, 11594-11598; (c) Y. Liu, M. Wang, W.-M. Ren, K.-K. He, Y.-C. Xu, J. Liu and X.-B. Lu, Macromolecules, 2014, 47, 1269-1276; (d) D. J. Darensbourg and S. J. Wilson, J. Am. Chem. Soc., 2011, 133, 18610-18613.

2 J. Langanke, A. Wolf, J. Hofmann, K. Bohm, M. A. Subhani, T. E. Muller, W. Leitner and C. Gurtler, Green Chem., 2014, 16, 1865-1870; M. Helou, J.-F. Carpentier and S. M. Guillaume, Green Chem., 2011, 13, 266-271.

3 (a) S. Fukuoka, M. Kawamura, K. Komiya, M. Tojo, H. Hachiya, K. Hasegawa, M. Aminaka, H. Okamoto, I. Fukawa and S. Konno, Green Chem., 2003, 5, 497-507. (b) S. Fukuoka, M. Tojo, H. Hachiya, M. Aminaka and K. Hasegawa, Polym. J., 2007, 39, 91114.

4 (a) K. Nozaki, Pure Appl. Chem., 2004, 76, 541-546. (b) G. W. Coates and D. R. Moore, Angew. Chem. Int. Ed., 2004, 43, 6618-6639. (c) G. W. Coates and R. C. Jeske, Handbook of Green Chemistry, Eds P. T. Anastas and R. H. Crabtree, 2009, 1, 343-373. (d) M. R. Kember, A. Buchard and C. K. Williams, Chem. Commun., 2011, 47, 141163. (e) S. Klaus, M. W. Lehenmeier, C. E. Anderson and B. Rieger, Coord. Chem. Rev., 2011, 255, 1460-1479. (f) P. P. Pescarmona and M. Taherimehr, Cat. Sci. Technol., 2012, 2, 2169-2187. (g) D. Darensbourg, in Synthetic Biodegradable Polymers, eds. B. Rieger, A. Künkel, G. W. Coates, R. Reichardt, E. Dinjus and T. A. Zevaco, Springer Berlin Heidelberg, 2012, vol. 245, ch. 135, pp. 1-27. (h) X.-B. Lu, W.M. Ren and G.-P. Wu, Acc. Chem. Res., 2012, 45, 1721-1735. (i) X.-B. Lu and D. J. 
Darensbourg, Chem. Soc. Rev., 2012, 41, 1462-1484. (j) M. I. Childers, J. M. Longo, N. J. Van Zee, A. M. LaPointe and G. W. Coates, Chem. Rev. 2014, 114, 8129-8152.

(a) D. J. Darensbourg, M. Ulusoy, O. Karroonnirum, R. R. Poland, J. H. Reibenspies and B. Cetinkaya, Macromolecules, 2009, 42, 6992-6998. (b) J. G. Kim, C. D. Cowman, A. M. LaPointe, U. Wiesner and G. W. Coates, Macromolecules, 2011, 44, 1110-1113. (c) M. Taherimehr, S. M. Al-Amsyar, C. J. Whiteoak, A. W. Kleij and P. P. Pescarmona, Green Chem., 2013, 15, 3083-3090. (d) D. C. Romain and C. K. Williams, Angew. Chem. Int. Ed., 2014, 53, 1607-1610.

C. T. Cohen, C. M. Thomas, K. L. Peretti, E. B. Lobkovsky and G. W. Coates, Dalton Trans., 2006, 237-249.

7 (a) K. Nozaki, K. Nakano and T. Hiyama, J. Am. Chem. Soc., 1999, 121, 11008-11009.

(b) M. Cheng, N. A. Darling, E. B. Lobkovsky and G. W. Coates, Chem. Commun., 2000, 2007-2008. (c) Z. Qin, C. M. Thomas, S. Lee and G. W. Coates, Angew. Chem. Int. Ed., 2003, 42, 5484-5487. (d) K. Nakano, K. Nozaki and T. Hiyama, J. Am. Chem. Soc., 2003, 125, 5501-5510. (e) K. Nakano, T. Hiyama and K. Nozaki, Chem. Commun., 2005, 1871-1873. (f) Y. Xiao, Z. Wang and K. Ding, Chem. Eur. J., 2005, 11, 3668-3678. (g) X.-B. Lu, L. Shi, Y.-M. Wang, R. Zhang, Y.-J. Zhang, X.-J. Peng, Z.-C. Zhang and B. Li, J. Am. Chem. Soc., 2006, 128, 1664-1674. (h) L. Shi, X.-B. Lu, R. Zhang, X.-J. Peng, C.-Q. Zhang, J.-F. Li and X.-M. Peng, Macromolecules, 2006, 39, 5679-5685. (i) G.-P. Wu, W.-M. Ren, Y. Luo, B. Li, W.-Z. Zhang and X.-B. Lu, J. Am. Chem. Soc., 2012, 134, 5682-5688. (j) W. C. Ellis, Y. Jung, M. Mulzer, R. Di Girolamo, E. B. Lobkovsky and G. W. Coates, Chem. Sci., 2014, 5, 4004-4011.

Handbook of Ring-Opening Polymerization, eds. P. Dubois, O. Coulembier and J.-M. Raquez, Wiley-VCH, Weinheim, 2009.

(a) T. Sakakura and K. Kohno, Chem. Commun., 2009, 1312-1330. (b) M. North, R. Pasquale and C. Young, Green Chem., 2010, 12, 1514-1539. (c) S.-H. Pyo, P. Persson, M. A. Mollaahma, K. Sörensen, S. Lundmark and R. Hatti-Kaul, Pure Appl. Chem., 2012, 84, 637-661. (d) H. Zhang, H.-B. Liu and J.-M. Yue, Chem. Rev., 2013, 114, 883898.

(a) G. Rokicki and P. G. Parzuchowski, in Polymer Science: A Comprehensive Reference, Eds. K. Matyjaszewski and M. Möller, Elsevier, Amsterdam, 2012, pp. 247 308. (b) H. Keul, in Handbook of Ring-Opening Polymerization, eds. P. Dubois, O. 
Coulembier and J.-M. Raquez, Wiley-VCH, Weinheim, 2009, Chapt. 12, pp. 307-327.

(c) S. Tempelaar, L. Mespouille, O. Coulembier, P. Dubois and A. P. Dove, Chem. Soc. Rev., 2013, 42, 1312-1336. (d) T. Endo, Y. Shibasaki and F. Sanda, J. Polym. Sci., A: Polym. Chem., 2002, 40, 2190-2198.

11 (a) G. Odian, Principles of Polymerization, 4th Edition, Wiley Interscience, John Wiley \& Sons, Inc., Hoboken, New Jersey, 2004. (b) L. Vogdanis, B. Martens, H. Uchtmann, F. Hensel and W. Heitz, Die Makromolekulare Chemie, 1990, 191, 465-472.

(a) O. Haba, H. Tomizuka and T. Endo, Macromolecules, 2005, 38, 3562-3563. (b) M. Azechi, K. Matsumoto and T. Endo, J. Polym. Sci., A: Polym. Chem., 2013, 51, 16511655.

(a) W. Guerin, A. Diallo, E. Kirillov, M. Helou, M. Slawinski, J.-M. Brusson, J.-F. Carpentier and S. M. Guillaume, Macromolecules 2014, 47, 4230-4235; (b) W. Guerin, S. Guillaume and J.-F. Carpentier, Eur. Pat. Appl. 13290095.2, 2013.

K. Tezuka, K. Komatsu and O. Haba, Polym J., 2013, 45, 1183-1187.

(a) M. Winkler, C. Romain, M. A. R. Meier and C. K. Williams, Green Chem., 2015,17, 300-306; (b) S. Honda, T. Mori, H. Goto and H. Sugimoto, Polymer, 2014, 55, $4832-$ 4836; (c) D. J. Darensbourg, W.-C. Chung, C. J. Arp, F.-T. Tsai and S. J. Kyran, Macromolecules, 2014, 47, 7347-7353.

Gaussian 09, Revision A.02, M. J. Frisch, G. W. Trucks, H. B. Schlegel, G. E. Scuseria, M. A. Robb, J. R. Cheeseman, G. Scalmani, V. Barone, B. Mennucci, G. A. Petersson, H. Nakatsuji, M. Caricato, X. Li, H. P. Hratchian, A. F. Izmaylov, J. Bloino, G. Zheng, J. L. Sonnenberg, M. Hada, M. Ehara, K. Toyota, R. Fukuda, J. Hasegawa, M. Ishida, T. Nakajima, Y. Honda, O. Kitao, H. Nakai, T. Vreven, J. A. Montgomery, Jr., J. E. Peralta, F. Ogliaro, M. Bearpark, J. J. Heyd, E. Brothers, K. N. Kudin, V. N. Staroverov, R. Kobayashi, J. Normand, K. Raghavachari, A. Rendell, J. C. Burant, S. S. Iyengar, J. Tomasi, M. Cossi, N. Rega, J. M. Millam, M. Klene, J. E. Knox, J. B. Cross, V. Bakken, C. Adamo, J. Jaramillo, R. Gomperts, R. E. Stratmann, O. Yazyev, A. J. Austin, R. Cammi, C. Pomelli, J. W. Ochterski, R. L. Martin, K. Morokuma, V. G. Zakrzewski, G. A. Voth, P. Salvador, J. J. Dannenberg, S. Dapprich, A. D. Daniels, O. Farkas, J. B. Foresman, J. V. Ortiz, J. Cioslowski and D. J. Fox, Gaussian, Inc., Wallingford CT, 2009.

Y. Zhao and D. G. Truhlar, J. Chem. Phys. 2006, 125, 194101. 
18 (a) R. Ditchfield, W. J. Hehre and J. A. Pople, J. Chem. Phys. 1971, 54, 724-728. (b) W. J. Hehre, R. Ditchfie and J. A. Pople, J. Chem. Phys. 1972, 56, 2257-2261. (c) P. C. Hariharan and J. A. Pople, Theor. Chim. Acta 1973, 28, 213-222.

19 S. Michaud and J. Viala, Tetrahedron, 1999, 55, 3019-3024.

A. Chatterjee, M. Sasikumar and N. N. Joshi, Synth. Commun., 2007, 37, 1727-1733.

C. K. Williams, L. E. Breyfogle, S. K. Choi, W. Nam, V. G. Young, M. A. Hillmyer and W. B. Tolman, J. Am. Chem. Soc., 2003, 125, 11350-11359.

E. Martin, P. Dubois and R. Jerome, Macromolecules, 2000, 33, 1530-1535.

The ceiling temperature of PCHC has been reported around $+100{ }^{\circ} \mathrm{C}$; see: G.-P. Wu, S.D. Jiang, X.-B. Lu, W.-M. Ren and S.-K. Yan, Chin. J. Polym. Sci., 2012, 30, 487-492. Another quite minor population was observed at $m / z+c a .78-80 \mathrm{Da}$, which could not be assigned. This population does not correspond to macromolecules decarboxylated or terminated by $\mathrm{HO}-\mathrm{H}$ instead of $\mathrm{BnO}-\mathrm{H}$.

For unclear reasons, this proved however not to be always the case, as the intensity of these terminal groups appeared much lower than expected in some experiments, preventing a systematic determination of $M_{\mathrm{n}}$ values by NMR. This may reflect initiation by other pathways.

C. T. Cohen, C. M. Thomas, K. L. Peretti, E. B. Lobkovsky and G. W. Coates, Dalton Trans., 2006, 237-249.

N. Ajellal, M. Bouyahyi, A. Amgoune, C. M. Thomas, A. Bondon, I. Pillin, Y. Grohens and J.-F. Carpentier, Macromolecules, 2009, 42, 987-993.

Similar decomposition close to the melting transition is observed for isotactic / syndiotactic CHDC; see reference $13 \mathrm{a}$. 